\title{
A Genetic Model for Absent Chylomicron Formation: Mice Producing Apolipoprotein B in the Liver, but Not in the Intestine
}

\author{
Stephen G. Young, ${ }^{\star \star \S}$ Candace M. Cham, ${ }^{*}$ Robert E. Pitas, ${ }^{\star \star \S}$ Betty J. Burri, " Andrew Connolly, ${ }^{\ddagger}$ Laura Flynn, ${ }^{*}$ \\ Anuradha S. Pappu, ' Jinny S. Wong, ${ }^{\ddagger}$ Robert L. Hamilton, ${ }^{\ddagger \star \star}$ and Robert V. Farese, Jr. ${ }^{\star \star \$}$ \\ * Gladstone Institute of Cardiovascular Disease, San Francisco, California 94141-9100; ${ }^{\ddagger}$ Cardiovascular Research Institute and \\ ${ }^{8}$ Department of Medicine, University of California, San Francisco, California 94143; "Western Human Nutrition Research Center, \\ United States Department of Agriculture, Presidio of San Francisco, San Francisco, California 94129; 'Department of Medicine, \\ University of Oregon Health Sciences Center, Portland, Oregon 97201; and **Department of Anatomy, University of California, San \\ Francisco, California 94143
}

\begin{abstract}
The formation of chylomicrons by the intestine is important for the absorption of dietary fats and fat-soluble vitamins (e.g., retinol, $\alpha$-tocopherol). Apo B plays an essential structural role in the formation of chylomicrons in the intestine as well as the VLDL in the liver. We have developed genetically modified mice that express apo $B$ in the liver but not in the intestine. By electron microscopy, the enterocytes of these mice lacked nascent chylomicrons in the endoplasmic reticulum and Golgi apparatus. Because these mice could not form chylomicrons, the intestinal villus enterocytes were massively engorged with fat, which was contained in cytosolic lipid droplets. These mice absorbed D-xylose normally, but there was virtually no absorption of retinol palmitate or cholesterol. The levels of $\alpha$-tocopherol in the plasma were extremely low. Of note, the absence of chylomicron synthesis in the intestine did not appear to have a significant effect on the plasma levels of the apo B-containing lipoproteins produced by the liver. The mice lacking intestinal apo $B$ expression represent the first genetic model of defective absorption of fats and fat-soluble vitamins and provide a useful animal model for studying nutrition and lipoprotein metabolism. (J. Clin. Invest. 1995. 96:2932-2946.) Key words: lipoproteins • cholesterol $\bullet$ intestinal fat malabsorption • tocopherol • apolipoprotein B
\end{abstract}

\section{Introduction}

The B apolipoproteins, apo B48 and apo B100, play important structural roles in the formation of lipoproteins in the intestine and the liver (1). In the intestine, apo B48 is essential for the packaging of alimentary lipids into chylomicrons. In the liver, apo B100 plays an obligatory structural role in the formation of the triglyceride-rich VLDL. When apo B is not made, as in homozygous hypobetalipoproteinemia, or cannot be secreted from cells, as in abetalipoproteinemia, chylomicrons, VLDL,

Address correspondence to Stephen G. Young, Gladstone Institute of Cardiovascular Disease, P.O. Box 419100, San Francisco, CA 941419100. Phone: 415-826-7500; Fax: 415-285-5632.

Received for publication 22 June 1995 and accepted in revised form 8 August 1995.

J. Clin. Invest.

(C) The American Society for Clinical Investigation, Inc.

0021-9738/95/12/2932/15 \$2.00

Volume 96, December 1995, 2932-2946 and LDL are absent from the blood $(2,3)$. Aside from liver and intestine, apo $\mathrm{B}$ is expressed during development in the visceral endoderm of the yolk sac (4-6), where the formation of apo B-containing lipoproteins plays a role in the nutrition of the developing embryo.

To further study the role of apo B in metabolism and development, our laboratory has recently generated several lines of genetically modified mice. In 1993, we used a 79.5-kb P1 bacteriophage clone spanning the human apo $\mathrm{B}$ gene to generate transgenic mice expressing human apo B (7). Even though the DNA fragment contained $19 \mathrm{~kb}$ of $5^{\prime}$ flanking sequences and $17.5 \mathrm{~kb}$ of $3^{\prime}$ flanking sequences, the tissue pattern of transgene expression was distinctly abnormal (7-9). Human apo B was expressed in the mouse liver (7-9) and yolk sac (Farese, R. V., Jr., S. Cases, S. L. Ruland, D. A. Sanan, H. J. Kayden, J. S. Wong, S. G. Young, and R. L. Hamilton, manuscript submitted for publication, and see reference 11) but was not expressed in the intestine. The absence of human apo B expression in the intestine of transgenic mice appeared to be complete; even using PCR, we could not detect human apo B expression in the cDNA of the intestines of these animals (10).

More recently, our laboratory used gene targeting techniques to generate apo B knockout mice (11). Mice heterozygous for a disrupted apo $B$ allele had an $\sim 70 \%$ reduction in the plasma levels of the apo B-containing lipoproteins and were protected from diet-induced hypercholesterolemia. Homozygotes had a lethal developmental abnormality, Farese and coworkers have recently used electron microscopy to examine the yolk sac membranes from wild-type and homozygous knockout embryos (Farese, R. V., Jr., S. Cases, S. L. Ruland, D. A. Sanan, H. J. Kayden, J. S. Wong, S. G. Young, and R. L. Hamilton, manuscript submitted for publication). In the wild-type mice, examination of the yolk sac visceral endoderm cells revealed large numbers of lipoproteins of VLDL size in the secretory pathway. In contrast, there was no lipoprotein formation in the yolk sacs of the homozygous knockout embryos. This inability to synthesize lipoproteins in the visceral endoderm cells was associated with a marked accumulation of cytosolic lipid droplets. We strongly suspect that the absence of lipoprotein formation in the yolk sac results in impaired embryo nutrition, causing the animals to die during development.

In this study, we sought to generate mice that synthesized apo $B$ in the liver, but not in the intestine, by crossing the apo $B$ knockout mice and the human apo B transgenic mice. We found that the human apo $B$ transgene, which was expressed in the yolk sac, could rescue the apo B knockout mice (11): mice carrying the human apo B transgene that were homozygous for the knockout mutation developed normally and, at birth, had normal size and weight. In addition to providing further evi- 
dence for the singular role of apo B expression in mouse development, the rescue experiment resulted in an important mouse model for studying apo B function and metabolism. Because the human apo $B$ transgene was not expressed in the intestines, the rescued mice synthesized human apo $B$ in the liver but lacked all apo B synthesis (mouse or human) in the intestine. In this study, we examined the effects of the absence of intestinal apo B expression and the resultant absence of chylomicron formation on intestinal function and lipoprotein metabolism.

\section{Methods}

Genetically modified mice. We used hemizygous human apo B transgenic mice $\left(\mathrm{HuBTg}^{+/ 0}\right)^{1}$ from transgenic line 1102 (7); the genetic background of these mice was $\sim 93 \% \mathrm{C} 57 \mathrm{Bl} / 6$ and $7 \% \mathrm{SJL}$. These mice express the human apo B transgene in the liver and to a lesser extent in the heart and kidney, but not at all in the intestine $(7,9)$. We also used heterozygous apo B knockout mice $\left(\mathrm{apoB}^{+/-}\right)$; the genetic background of these mice was 50\% 129/Sv and 50\% C57Bl/6 (11). Heterozygous knockout mice and the hemizygous human apo B transgenic mice were crossed to generate human apo B transgenic mice that were heterozygous for the knockout mutation $\left(\mathrm{HuBTg}^{+/ 0}\right.$, $a p o B^{+/-}$). The latter mice were intercrossed to generate human apo $B$ transgenic mice that were homozygous for the knockout mutation. These mice (genotypes $\mathrm{HuBTg}^{+/+}, a_{0 o B^{-1-}}$ or $\mathrm{HuBTg}^{+/ 0}, a_{0 o B^{-1-}}$ ) expressed human apo $B$ in the liver but lacked apo $B$ (mouse or human) in the intestine. Genotyping of mice was performed by Southern analysis of tail DNA $(7,11)$.

Pathological studies. Mice were killed at 2 wk or at 2-3 mo of age. Sections of 10- $\mu \mathrm{m}$ thickness were prepared from paraffin-embedded liver, intestine, and other tissues and stained with hematoxylin and eosin. In one experiment, 15- and 20-d-old mouse embryos were analyzed in a similar manner. To detect fat, tissues were fixed in $10 \%$ neutralbuffered formalin, and $10-\mu \mathrm{m}$ thick frozen sections were cut on a cryostat (Reichert-Jung, Nussloch, Germany) and stained with Oil Red O.

For electron microscopy, 2-wk-old $\mathrm{HuBTg}^{+/ 0}$, apoB ${ }^{-1-}$ mice and a 2-mo-old $\mathrm{HuBTg}^{+/ 0}$, apoB ${ }^{-1-}$ mouse, and age-matched $\mathrm{HuBTg}^{+/ 0}$ mice were used. The suckling mice were removed from their mother for 3$6 \mathrm{~h}$ before being killed. The mice were anesthetized by peritoneal injection of pentobarbital $(\sim 2 \mathrm{mg} / 25 \mathrm{~g}$ body wt $)$, and the heart was surgically exposed for intravascular perfusion of fixative. A 20-gauge cannula was inserted into the left ventricle; the right atrium was snipped open, and 3-5 ml of $0.1 \mathrm{M}$ cacodylate buffer was pumped into the left ventricle at a flow rate of $8-15 \mathrm{ml} / \mathrm{min}$ to flush the blood from the mouse. We then infused fixative (1.5\% glutaraldehyde, $4 \%$ polyvinylpyrrolidone, $0.05 \%$ calcium chloride, $0.1 \mathrm{M}$ cacodylate, $\mathrm{pH} 7.4$ ) for $10 \mathrm{~min}$. Tissue was excised into fixative and subsequently stained for lipid by the imidazole-buffered osmium tetroxide procedure (12). Tissues were block stained in $2 \%$ aqueous uranyl acetate for $1 \mathrm{~h}$ at $4^{\circ} \mathrm{C}$ before embedding in Epon (DuPont, Wilmington, DE). Ultrathin sections were stained for $5 \mathrm{~min}$ with $0.8 \%$ lead citrate and photographed in an electron microscope (101; Siemens/CTI Corp., Knoxville, TN).

Body compositions (percentage of body mass consisting of fat) of the carcasses of $\mathrm{HuBTg}^{+/ 0}, a p o B^{-1-}$ mice and unaffected littermates were determined in the laboratory of Dr. Janis Fisler (University of California, Los Angeles) exactly as previously described (13).

Analysis of lipoprotein phenotype. Total and HDL cholesterol levels and triglyceride levels were measured on fresh plasma samples after a 4-h fast $(7,11)$. Agarose gel electrophoresis of plasma samples was performed as previously described (14). The agarose gels were either stained for lipid with Fat Red 7B (Sigma Chemical Co., St. Louis, MO) or used for Western blots which were probed with a ${ }^{125}$ I-labeled human

1. Abbreviations used in this paper: BHT, butylated hydroxytoluene; ER, endoplasmic reticulum; HuBtg, human apo B transgenic. apo B-specific mAb, C1.4 (15), or a ${ }^{125} \mathrm{I}$-labeled rabbit anti-rat apo B IgG, which binds to mouse apo B. The anti-rat apo B antibody was passed over a human LDL-Sepharose $4 B$ column to reduce the binding of the antibody to human apo B (7). To further reduce the binding of the antibody to human apo B, the antibody was preincubated with $20 \mu \mathrm{l}$ of human plasma for $1 \mathrm{~h}$ before adding the antibody to the nitrocellulose membrane. The amount of radioactivity within the pre- $\beta$ and $\beta$-lipoproteins was assessed using a phosphorimager (Bio-Imaging Analyzer, BAS 1000 with MacBAS, Fuji Medical Systems, USA, Inc., Stamford, CT).

To determine the distribution of cholesterol within different plasma lipoprotein fractions, $250 \mu \mathrm{l}$ of plasma was subjected to size fractionation on a Superose $610 / 30$ column as described elsewhere (7). The distribution of human apo B within each column fraction was assessed on Western blots of 3-12\% gradient SDS-polyacrylamide gels and probed using ${ }^{125} \mathrm{I}$-labeled antibody $\mathrm{C} 1.4$. The amount of radioactivity in the apo B100 bands was measured using a phosphorimager (Fuji Medical Systems).

The quantity of human apo B in the plasma of the transgenic mice was assessed using a solid-phase competitive RIA, exactly as previously described $(7,10)$. In this assay, performed in 96-well polyvinylchloride plates, we tested the ability of plasma samples to compete with ${ }^{125} \mathrm{I}$ labeled human LDL for binding to the human apo B-specific mAb, 1D1 (16). Antibody 1D1 is a human apo B-specific mAb that binds in the vicinity of human apo B amino acid residue 500 (16). To judge the amount of apo $\mathrm{AI}$ in the plasma of mice, we subjected $0.25-\mu \mathrm{l}$ plasma samples to size separation on 4-20\% SDS-polyacrylamide gels, and then performed Western blots (17) using a rabbit antiserum to rat apo AI, provided by Dr. Nick Davidson (University of Chicago, Chicago, IL).

Retinol palmitate absorption test. A total of 5,000 $\mathrm{U}$ of retinol palmitate (Sigma Chemical Co.) mixed in $100 \mu \mathrm{l}$ of canola oil was delivered into the stomachs of anesthetized mice using an oral-gastric catheter. Blood samples were obtained from the retroorbital plexus before administration of the retinol palmitate, and 2, 4, 8, and $12 \mathrm{~h}$ after the administration of retinol palmitate. The content of retinol palmitate in each plasma sample was assessed by HPLC. HPLC standards (retinol acetate, retinol, retinol palmitate, $\alpha$-tocopherol, $\beta$-carotene), as well as ammonium sulfate, butylated hydroxytoluene (BHT), and SDS were purchased from Sigma Chemical Co. HPLC-grade solvents (water, hexane, acetonitrile, methanol, tetrahydrofuran, and ethanol) were purchased from Baxter Scientific Products (Hayward, CA). Mobile phases were made by mixing acetonitrile, tetrahydrofuran, methanol, $1 \%$ ammonium acetate, and BHT in the ratios: 85:5:5:5:0.05 ( $\mathrm{vol} / \mathrm{vol} / \mathrm{vol} /$ vol/wt) for mobile phase A and 55:35:5:5:0.05 ( $\mathrm{vol} / \mathrm{vol} / \mathrm{vol} / \mathrm{vol} / \mathrm{wt}$ ) for mobile phase B. All solvents were filtered through $0.2-\mu \mathrm{m}$ nylon filters (Gelman Sciences Inc., Ann Arbor, MI) before use.

Plasma was frozen at $-75^{\circ} \mathrm{C}$ until use, then thawed under gold lights to preserve light-sensitive compounds. Plasma samples (40-100 $\mu \mathrm{l}$, depending on availability) were mixed with $400 \mu$ l of SDS-ethanolBHT solution and vortexed for $60 \mathrm{~s}$. Then, $500 \mu \mathrm{l}$ of hexane containing $0.1 \% \mathrm{BHT}$ was added and vortexed for $60 \mathrm{~s}$. The mixture was then centrifuged $(7,000 \mathrm{~g})$ at $24^{\circ} \mathrm{C}$ for $5 \mathrm{~min}$ in a refrigerated centrifuge (RC5C; Du Pont Instruments-Sorvall Biomedical Division, Wilmington, DE). The upper hexane layer was transferred to an amber glass HPLC vial. This extraction was repeated once. The hexane layers were combined and dried under nitrogen. The dried extract was reconstituted with $100 \mu \mathrm{l}$ of mobile phase B containing retinol acetate as an internal standard.

Retinol, retinol palmitate, $\alpha$-tocopherol, $\gamma$-tocopherol, and the carotenoids were assayed by reversed-phase liquid chromatography using a modification of a previously described method (18). Chromatography was performed on an HPLC (System Gold; Beckman Instruments Inc., Fullerton, CA) with a 126 Programmable Solvent Module, $507 \mathrm{Au}$ tosampler, and 168 Diode Array Detector. HPLC peaks were detected and measured with chromatography software (SystemGold, version 7.1; Beckman). Autosampler temperature was controlled at $10^{\circ} \mathrm{C}$ with a refrigerated water bath (RTE-100; Neslab Instruments Inc., Portsmouth, 
$\mathrm{NH}$ ). The chromatography column used was a Novapak $\mathrm{C}_{18}$ column preceded by a Novapak $C_{18}$ guard column (Millipore Corp., Waters Chromatography, Milford, MA). A gradient at a constant flow rate of $1.2 \mathrm{ml} / \mathrm{min}$ was used to separate the compounds of interest. The gradient profile was: from $100 \%$ A to $100 \% \mathrm{~B}$ in $27 \mathrm{~min}$ using a linear gradient (curve 3), remaining at $100 \% \mathrm{~B}$ for $10 \mathrm{~min}$, then to $40 \% \mathrm{~A}$ and $60 \%$ $B$ in $1 \mathrm{~min}$, then $100 \% \mathrm{~A}$ in $5 \mathrm{~min}$ (curve 3 ), remaining at $100 \% \mathrm{~A}$ for $4 \mathrm{~min}$. The total run time was $47 \mathrm{~min}$. The HPLC effluent was monitored for retinoids at $325 \mathrm{~nm}$; tocopherols at $300 \mathrm{~nm}$; and carotenoids at $452 \mathrm{~nm}$. Peaks were identified by comparison of retention times to standards. Mouse plasma samples were identified by number and run double-blind in random order.

Measurement of intestinal cholesterol absorption. Assessment of intestinal cholesterol absorption was performed according to the procedures recently described by Turley et al. (19). Mice were housed in metabolic cages with free access to food and water. A mixture of [22,23$\left.{ }^{3} \mathrm{H}\right] \boldsymbol{\beta}$-sitostanol (American Radiolabeled Chemicals, Inc., St. Louis, MO) and $\left[4-{ }^{14} \mathrm{C}\right]$ cholesterol (Amersham Corp., Arlington Heights, IL) was prepared as previously described and mixed in safflower oil. We used $\left[{ }^{3} \mathrm{H}\right] \beta$-sitostanol, rather than $\left[{ }^{3} \mathrm{H}\right] \beta$-sitosterol, because it is absorbed much more poorly from the intestine (19). A total of $100 \mu \mathrm{l}$ of safflower oil containing $1.67 \mu \mathrm{Ci}$ of $\left[{ }^{3} \mathrm{H}\right] \beta$-sitostanol and $0.67 \mu \mathrm{Ci}$ of $\left[{ }^{14} \mathrm{C}\right]$ cholesterol was administered to each mouse by oral-gastric cannulation. Feces were collected for $7 \mathrm{~d}$, dried in a $65^{\circ} \mathrm{C}$ oven overnight, and ground to a fine powder using a mortar and pestle. A total of $1 \mathrm{~g}$ of feces was extracted with chloroform/methanol (2:1) and petroleum ether as previously described (19), and the level of radioactivity was measured in a $\beta$-counter, with appropriate controls for quenching. Cholesterol absorption was calculated as:

$\left[{ }^{14} \mathrm{C}\right]$ cholesterol $/\left[{ }^{3} \mathrm{H}\right] \beta$-sitostanol (dosing mixture) $\left[{ }^{14} \mathrm{C}\right]$ cholesterol $/\left[{ }^{3} \mathrm{H}\right] \beta$-sitostanol (feces)

$\left[{ }^{14} \mathrm{C}\right]$ cholesterol $/\left[{ }^{3} \mathrm{H}\right] \beta$-sitostanol (dosing mixture)

The $\left[{ }^{3} \mathrm{H}\right] \beta$-sitostanol $/\left[{ }^{14} \mathrm{C}\right]$ cholesterol absorption test was used for our studies rather than an alternative method (involving the simultaneous administration of intragastric and intravenous boluses of $\left[{ }^{3} \mathrm{H}\right]$ cholesterol and $\left[{ }^{14} \mathrm{C}\right]$ cholesterol, respectively) based on the advice of Dr. Stephen Turley (University of Texas SW, Dallas, TX, personal communication).

Measurement of plasma mevalonate levels. To obtain an indirect assessment of the amount of de novo cholesterol biosynthesis, we measured plasma mevalonate levels in mice lacking apo B in the intestine. In the first experiment, we obtained heparinized plasma samples in the middle of the afternoon (after a 4-h fast) from four $\sim 3$-mo-old mice lacking apo $B$ in the intestines and four age- and sex-matched hemizygous human apo B transgenic animals. In the second experiment, the animals were fasted overnight, and blood samples were obtained at 8:00 a.m. Plasma mevalonate levels were measured as previously described (20). Briefly, plasma ultrafiltrates were prepared using Ultrafree-MC filters (Millipore Corp.) $(10,000$ NMWL regenerated cellulose membrane) filters at $4^{\circ} \mathrm{C}$. Corrections were made for variations in the recovery of plasma mevalonate in the ultrafiltrates by measuring the recovery of a trace amount of $\left[{ }^{3} \mathrm{H}\right]$ mevalonate from plasma as previously described (20). Concentrations of mevalonate were measured in plasma ultrafiltrates using a modification of the radioenzymatic method of Popjak et al. (21), which measures the phosphorylation of mevalonate to $\left[5-{ }^{32} \mathrm{P}\right]$ phosphomevalonate by mevalonate kinase and $\left[{ }^{32} \mathrm{P}\right] \mathrm{ATP}$.

Analysis of the plasma fatty acid composition. To test for essential fatty acid deficiency, we analyzed the plasma fatty acids in four adult mice lacking apo $B$ in the intestine and four adult control mice. We also analyzed tissue fatty acid levels (in lung, heart, spleen, liver, and kidney) in a 3-mo-old mouse lacking apo B in the intestine and in a control mouse. The total plasma and tissue fatty acid composition was analyzed essentially as described (22). Briefly, plasma (350 $\mu \mathrm{l})$ was freeze-dried and extracted with chloroform/methanol (2:1). Tissues were sonicated after the addition of a small volume of water, lyophilized, and extracted with chloroform/methanol (2:1). The extracts were dried and transesterified overnight at $37^{\circ} \mathrm{C}$ with a mixture of $3 \mathrm{~N}$ methanolic $\cdot \mathrm{HCl}$ (Supelco, Inc., Bellefonte, PA) and toluene (4:1). Methyl esters were extracted with hexane, purified by TLC, and analyzed by gas-liquid chromatography (22).

Measurement of plasma $\alpha$-tocopherol levels. Plasma $\alpha$-tocopherol levels in $\mathrm{HuBTg}^{+10}$, apoB $^{-1-}$ mice and control animals were determined by Dr. Maret Traber (University of California, Berkeley) by HPLC with an electrochemical detector (23), which permits accurate quantification of low levels of $\alpha$-tocopherol.

$D$-xylose absorption test. To assess the ability of the intestine to absorb a simple carbohydrate, we performed D-xylose absorption tests on two groups of animals: four control mice (hemizygous transgenic mice) and four mice lacking apo $B$ in the intestine. The study was performed using the techniques recommended by Zimmer et al. (24). Each group of four mice was housed in a metabolic cage, and the mice were given free access to a $1.0 \%$ solution of $D$-xylose for $24 \mathrm{~h}$. Urine was collected for the $24-\mathrm{h}$ period, and the volumes were recorded. The amount of D-xylose in the urine was determined by a colorimetric assay described by Eberts et al. (25). The D-xylose assay was standardized using a series of dilutions of $0.5 \% \mathrm{D}$-xylose solution in water-saturated benzoic acid. As a blank for the colorimetric assay, we used urine that had been collected from the mice before the administration of the Dxylose. Samples were read in a spectrophotometer. From the amount of D-xylose that each group consumed, the urine volume, and the concentration of D-xylose in the urine, we calculated the percentage of the administered D-xylose that was recovered in the urine. This test was performed twice, $4 \mathrm{~d}$ apart, on each group of animals.

\section{Results}

Phenotype of suckling mice lacking apo $B$ in the intestine. In prior studies, we used a 79.5-kb fragment of human genomic DNA to generate human apo B transgenic mice in which the human apo $B$ transgene was expressed in the liver $(7,9)$ and yolk sac $(11)$ but not in the intestine $(7,9)$, and we used genetargeting techniques to generate apo B knockout mice (11). We predicted that human apo B transgenic mice that were homozygous for the knockout mutation (genotypes $\mathrm{HuBTg}^{+/+}$, $a p o B^{-1-}$ or $\mathrm{HuBTg}^{+/ 0},{a p o B^{-1-}}$ ) would express human apo B in the liver and yolk sac but would lack all apo $B$ production (mouse or human) in the intestine. To test this prediction, we mated human apo B transgenic mice that were heterozygous for the knockout mutation $\left(\mathrm{HuBTg}^{+/ 0}, \mathrm{apoB}^{+/-}\right)$and analyzed their offspring. Mendelian genetics would predict that 4 of 16 embryos would be homozygous for the knockout mutation, and of these, three would carry the human apo B transgene and one would not. Because the homozygote lacking the human apo B transgene would lack yolk sac expression of apo B and would therefore not survive development, we predicted that 3 of 15 viable offspring (20\%) would carry the human apo B transgene, be homozygous for the knockout, and be genetically incapable of synthesizing apo B in the intestine.

All of the offspring from the $\mathrm{HuBTg}^{+/ 0},{a p o B^{+/-}}$intercrosses were of normal size and appearance at birth. However, within $24 \mathrm{~h}$, the mice that were incapable of intestinal apo B synthesis could be distinguished from littermates because they developed a protuberant, white abdominal cavity, which resulted from accumulated fat within the intestinal enterocytes and nonabsorbed maternal milk within the intestinal lumen. 40 of 236 offspring $(17 \%)$ from $\mathrm{HuBTg}^{+/ 0}, a \mathrm{abB}^{+/-}$intercrosses displayed this dramatic phenotype. By Southern analysis, all of these animals were homozygous for the knockout mutation and carried the human apo B transgene. By 2-3 d of age, the animals with the white, protuberant abdomens developed significant growth retardation. Fig. $1 \mathrm{~A}$ shows a typical growth-retarded $\mathrm{HuBTg}^{+/ 0}, a p o B^{-1-}$ mouse and an unaffected littermate, both 

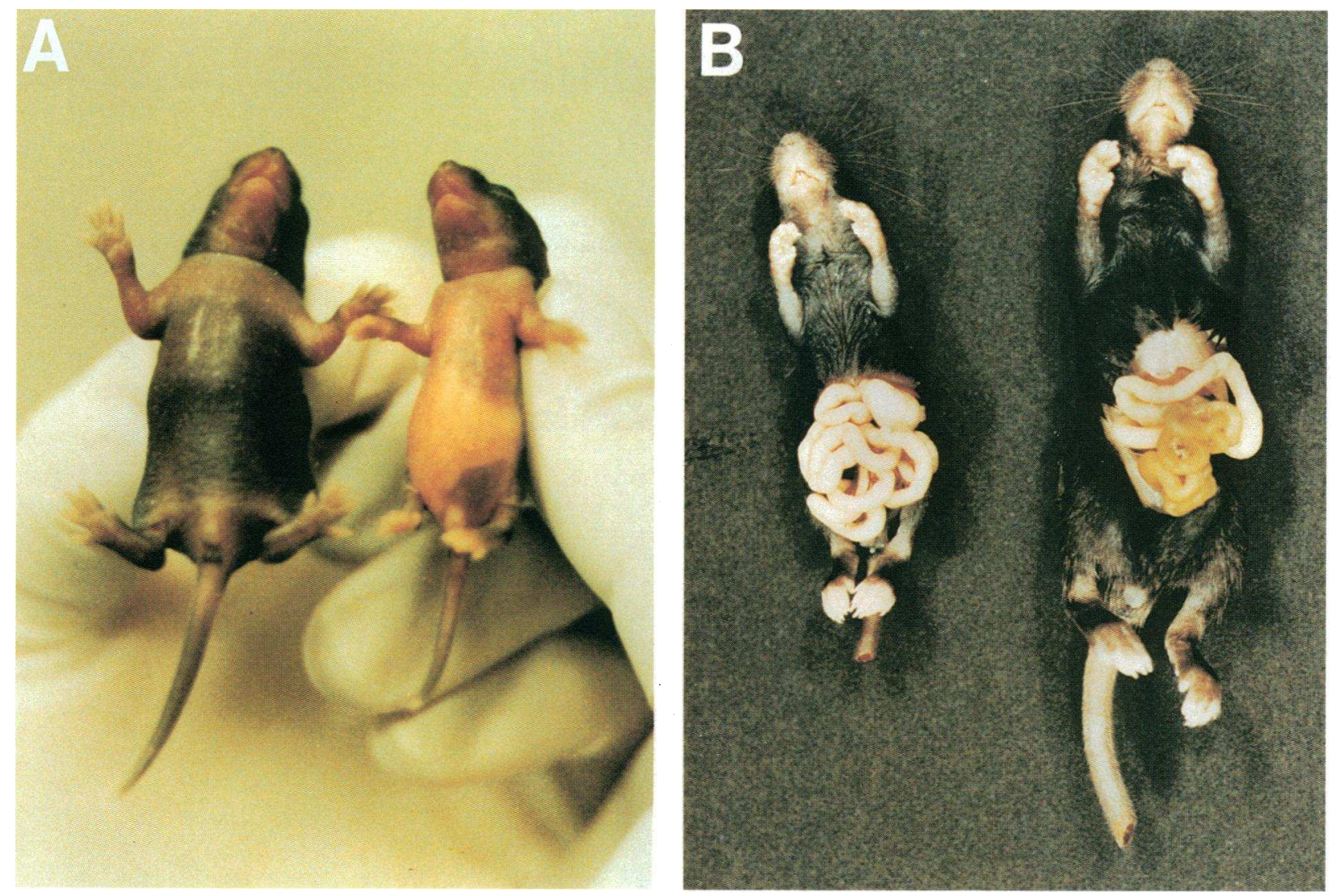

Figure 1. Photographs of 6-d-old $(A)$ and 2-wk-old $(B)$ suckling mice. $(A)$ The mouse on the right lacks apo B synthesis in the intestine (genotype $\left.\mathrm{HuBTg}^{+/ 0}, a p o B^{-1-}\right) .(B)$ The mouse on the left lacks apo $B$ synthesis in the intestine.

at $6 \mathrm{~d}$ of age. At $2 \mathrm{wk}$ of age, the entire length of the intestine remained white and the growth retardation was even more pronounced (Fig. $1 B$ ). The white color of the small and large intestines did not change when the contents of the intestine were flushed from the lumen, indicating that this finding was largely due to the accumulation of fats within the wall of the intestines. The calibers of the small and large intestines were invariably enlarged, and the intestines constituted $\sim 20 \%$ of the body weight, versus $\sim 10 \%$ for the wild-type or $\mathrm{HuBTg}^{+/ 0}$ mice. The suckling animals were invariably emaciated; the mean percentage of the body mass consisting of fat in three $\mathrm{HuBTg}^{+/ 0}, a p o B^{-1-}$ mice was $3.6 \%$, versus $12.1 \%$ in three unaffected littermates.

On microscopic examination, the intestinal pathology in the 2-wk-old $\mathrm{HuBTg}^{+/ 0}, a p o B^{-1-}$ mice was essentially identical to that reported for abetalipoproteinemia $(26,27)$ : the villus enterocytes along the entire length of the small intestines were engorged with fat (compare Fig. 2, $A$ and $B$ ). Fat accumulation was absent in the crypt cells but was increasingly abundant in cells that had migrated from the crypt towards the villus tip. As expected, the villus enterocytes stained brightly with Oil Red O (compare Fig. 2, $C$ and $D$ ). The enterocytes of the colon contained smaller amounts of fat (compare Fig. 2, $E$ and $F$ ). The livers of the 2-wk-old suckling HuBTg ${ }^{+10}$ mice showed moderate fat accumulation within hepatocytes. In contrast, the livers of the suckling $\mathrm{HuBTg}^{+/ 0}$, apoB ${ }^{-1-}$ mice had little, if any, fat accumulation (data not shown). In addition to the intestinal and liver abnormalities, microscopic examination of the 2-wk-old HuBTg ${ }^{+/ 0}, a p o B^{-1-}$ mice revealed that they were completely deficient in subcutaneous and mesenteric white adipose tissue. However, we noted no deficiency of abdominal brown adipose tissue.

Adult mice lacking intestinal apo B. Approximately onehalf to two-thirds of the mice lacking apo $B$ in the intestine became emaciated and died within the first $3 \mathrm{wk}$ of life. The surviving animals were given free access to a chow diet at 21 $\mathrm{d}$ of age, but because of their small size, were not removed from their mother's cage until they were 30-35 d old. On a chow diet, the HuBTg ${ }^{+/ 0}, a p o B^{-1-}$ mice gained strength, grew rapidly, and ultimately weighed as much as their littermates. On a practical level, we were able to obtain one healthy adult $\mathrm{HuBTg}^{+/ 0}, \mathrm{apoB}^{-1-}$ mouse for every two litters from intercrosses of HuBTg ${ }^{+/ 0}, a p o B^{+1-}$ mice. The abdominal cavities of the adult $\mathrm{HuBTg}^{+/ 0}$, apoB ${ }^{-1-}$ mice remained protuberant, although this feature became less prominent as the animals grew to a size of 30-35 g. We observed that the production of feces in the adult $\mathrm{HuBTg}^{+/ 0}, a p o B^{-1-}$ mice appeared to be greater than their littermates. Therefore, we compared the amount of food consumed by adult $\mathrm{HuBTg}^{+/ 0}$, apoB $^{-1-}$ and $\mathrm{HuBTg}^{+/ 0}$ mice. Two female HuBTg ${ }^{+/ 0}, a_{p o B}{ }^{-1-}$ mice consumed 0.295 $\mathrm{g}$ of chow/g body wt and produced $0.062 \mathrm{~g}$ of feces/g body wt per $24 \mathrm{~h}$. In contrast, two female $\mathrm{HuBTg}^{+/ 0}$ mice consumed $0.17 \mathrm{~g}$ of chow $/ \mathrm{g}$ body wt and produced $0.032 \mathrm{~g}$ feces $/ \mathrm{g}$ body wt. Similar differences were observed in male $\mathrm{HuBTg}^{+/ 0}$, $a_{p o B}{ }^{-1-}$ mice and controls, on several occasions. The HuBTg ${ }^{+/ 0}$, apoB $^{-1-}$ mice also produced $\sim 30 \%$ more urine than the $\mathrm{HuBTg}^{+/ 0}$ mice.

Although most of the chow-fed $\mathrm{HuBTg}^{+/ 0},{a p o B^{-1-}}$ mice 

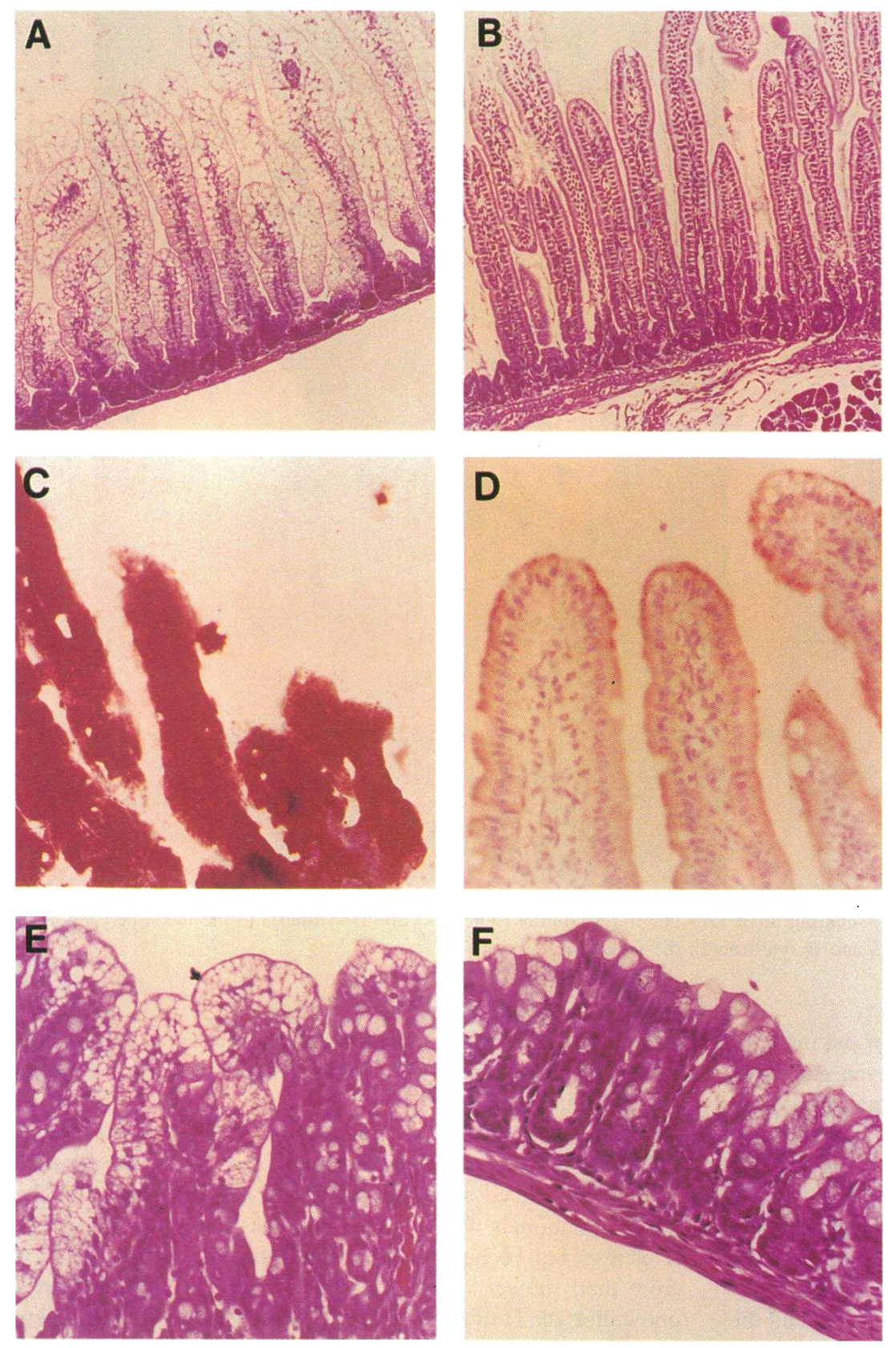

Figure 2. Histologic sections from the intestines of 2-wk-old mice. (A) Hematoxylin and eosin-stained section from the duodenum of a 2-wk-old $\mathrm{HuBTg}^{+/ 0}$, apoB ${ }^{-1-}$ mouse. (B) A hematoxylin and eosin-stained section from the duodenum of a 2wk-old $\mathrm{HuBTg}^{+/ 0}$ mouse. (C) Oil Red O-stained section from the duodenum of a 2-wk-old $\mathrm{HuBTg}^{+/ 0}$, apoB ${ }^{-1-}$ mouse. (D) An Oil Red Ostained section from the duodenum of a 2-wk-old $\mathrm{HuBTg}^{+/ 0}$ mouse. (E) A hematoxylin and eosinstained section from the colon of a 2-wk-old HuBTg $^{+10}$, apoB ${ }^{-1-}$ mouse. $(F) \mathrm{A}$ hematoxylin and eosin-stained section from the colon of a 2-wk-old $\mathrm{HuBTg}^{+/ 0}$ mouse.

appeared healthy, $\sim 10 \%$ of these mice developed hydrocephalus, a phenotype that has been noted previously in $a p o B^{-1-}$ mouse embryos (11) and in gene-targeted mice expressing apo B70 (28). Hydrocephalus, which could usually be identified by 21-28 d of age, was associated with lethargy and slow growth and generally resulted in death by 3-4 mo of age.

When chow-fed adult animals were killed at 3 mo of age, the small intestines remained white and grossly dilated, but the colon appeared to be normal. Histologic sections revealed marked fat accumulation in the enterocytes of the duodenum (Fig. 3, $A$ and $B$ ) and jejunum (Fig. $3 C$ ). In contrast to the findings in suckling mice, the terminal ileum contained smaller amounts of lipid (Fig. $3 \mathrm{D}$ ), and the colon was free of lipid accumulation (data not shown). By light microscopy, the livers of the $\mathrm{HuBTg}^{+/ 0}, a_{p o B}{ }^{-1-}$ appeared normal.

In one experiment, we examined hematoxylin and eosin- stained sections of the abdomens of 15- and 20-d embryos. The intestines of the $\mathrm{HuBTg}^{+/ 0},{a p o B^{-/}}^{-}$embryos appeared normal, without fat accumulation, indicating that significant fat accumulation in the enterocytes did not occur before birth.

Ultrastructural studies. The duodenums of 2-wk-old suckling mice (that had been deprived of nursing for $\sim 3-6 \mathrm{~h}$ ) and adult mice were examined by electron microscopy. In the HuBTg ${ }^{+/ 0}$ mice, the enterocytes contained only a few cytosolic lipid droplets, and the secretory pathway (smooth and rough endoplasmic reticulum [ER] and Golgi apparatus) contained numerous VLDL- and chylomicron-sized particles $(\sim 500-$ $1500 \AA$ in diameter) (Fig. $4 \mathrm{~A}$ ). In contrast, the enterocytes of the $\mathrm{HuBTg}^{+/ 0}, a p o B^{-1-}$ mice were largely filled with cytosolic lipid droplets (Fig. $4 B$ ). These lipid droplets lacked a cell membrane and were especially prominent in the top two-thirds of the villus (furthest from the crypt). The difference between 

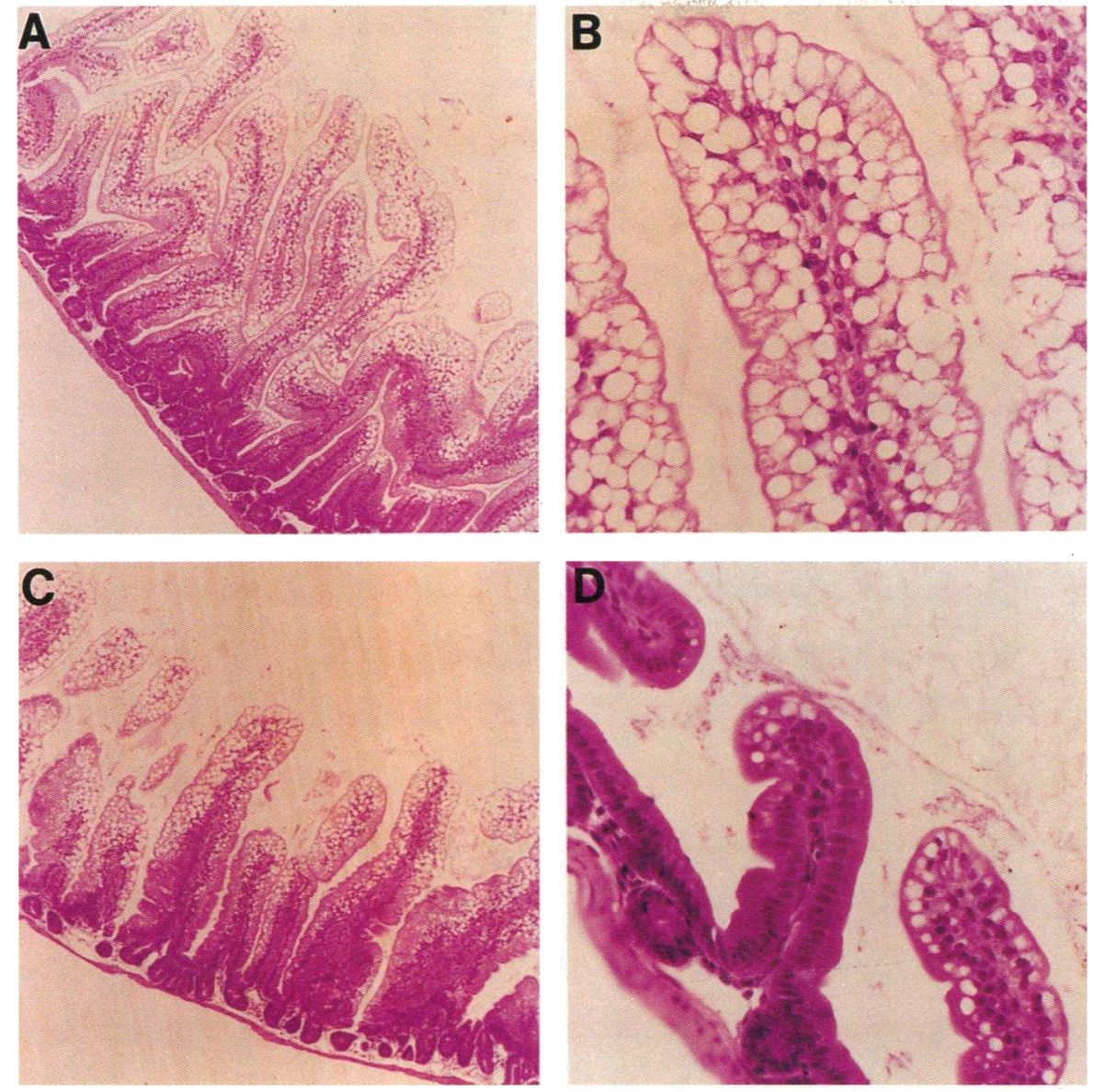

Figure 3. Hematoxylin and eosin-stained histologic sections of the intestines of a 10wk-old $\mathrm{HuBTg}^{+/ 0}, a p o B^{-1-}$ mouse. $(A)$ The duodenum at low power. $(B)$ The duodenum at higher power. $(C)$ The jejunum. $(D)$ The terminal ileum. the thickness of the lipid bilayer of a cell membrane $(\sim 120$ $\AA$ ) and the monomolecular phospholipid surface film ( $<60 \AA)$ that surrounds a cytosolic lipid droplet is illustrated in Fig. $5 B$. Both rough and particularly smooth ER were absent or greatly diminished in quantity (Fig. $4 \mathrm{~B}$ ), and only rarely were lipidstaining particles observed within the luminal spaces of the ER or Golgi apparatus. Many lipid-staining particles of VLDL and chylomicron size were evident in the Golgi cisternae of enterocytes of both suckling and weaned $\mathrm{HuBTg}^{+/ 0}$ mice (Fig. $5 A$ ) whereas the Golgi cisternae of $\mathrm{HuBTg}^{+/ 0}, a p o B^{-1-}$ enterocytes nearly always lacked these lipid-staining particles (Fig. $5 B$ ). In rare instances, however, small amounts of lipid-staining material were observed in the Golgi cisternae of $\mathrm{HuBTg}^{+/ 0}$, $a p o B^{-1-}$ enterocytes (data not shown). In the HuBTg ${ }^{+/ 0}$ mice, many VLDL- and chylomicron-sized particles $(\sim 700-2200$ $\AA$ ) were also observed outside of the enterocytes in the connective tissue spaces of the villus (Fig. $6 \mathrm{~A}$ ). In ultrathin sections of the base of enterocytes $\mathrm{HuBTg}^{+/ 0}, a p o B^{-1-}$ mice, rare lipidstaining particles were observed (Fig. $6 B$ ); however, these usually appeared irregular in shape.

Lipids and lipoproteins in mice lacking intestinal apo $B$. We measured triglyceride, cholesterol, and HDL cholesterol levels of fresh plasma samples from chow-fed male and female $\mathrm{HuBTg}^{+/ 0}$ and $\mathrm{HuBTg}^{+/ 0}$, apoB $^{-1-}$ mice at $2-3$ mo of age (Table I). The mean total cholesterol levels in the $\mathrm{HuBTg}^{+10}$, $a p o B^{-1-}$ mice were lower than those in the $\mathrm{HuBTg}^{+/ 0}$ mice, although this difference did not achieve statistical significance. The lower total cholesterol levels in the $\mathrm{HuBTg}^{+/ 0}, a p o B^{-1-}$ mice were largely, if not completely, explained by much lower
HDL cholesterol levels in those animals (Table I). The triglyceride levels in the $\mathrm{HuBTg}^{+/ 0}$ and $\mathrm{HuBTg}^{+/ 0}$, apoB ${ }^{-1-}$ mice were similar (Table I).

To analyze the distribution of lipids within the plasma lipoproteins, we examined mouse plasma samples by agarose gel electrophoresis. Fig. $7 \mathrm{~A}$ shows a Fat Red 7B-stained agarose gel of the plasma from a wild-type mouse, a human apo B transgenic mouse $\left(\mathrm{HuBTg}^{+/ 0}\right)$, and two $\mathrm{HuBTg}^{+/ 0}$, apoB $^{-1-}$ mice. The quantity of $\beta$-migrating lipoproteins in the plasma of the $\mathrm{HuBTg}^{+/ 0}$, apoB ${ }^{-1-}$ mice was identical to that in the $\mathrm{HuBTg}^{+/ 0}$ mice. Furthermore, Western blots probed with a human apo B-specific antibody revealed that the plasma from the $\mathrm{HuBTg}^{+/ 0}, a p o B^{-1-}$ mice contained as much human apo B as the plasma from the $\mathrm{HuBTg}^{+/ 0}$ mice (Fig. $7 B$ ). To detect mouse apo $B$, we used a rabbit antibody against rat apo B (7). To minimize the binding of the antibody to human apo $\mathrm{B}$, the antibody had been passed over a human LDL-Sepharose 4B column. To further minimize the binding of this antibody to human apo B, the antibody was incubated with $20 \mu \mathrm{l}$ of human plasma before incubating it with the nitrocellulose membrane. As expected, the antibody bound strongly to mouse apo $B$ in the plasma of $\mathrm{HuBTg}^{+/ 0}$ mice (Fig. $7 C$, lane 1 ). In spite of the immunoabsorption steps, however, the antibody bound faintly to the human apo $B$ in human plasma (lane 2) and also faintly to the plasma of $\mathrm{HuBTg}^{+/ 0}, a p o B^{-1-}$ mice (Fig. $7 C$, lane 3). The faint signal observed with the $\mathrm{HuBTg}^{+/ 0}$, apoB ${ }^{-1-}$ mouse plasma almost certainly represented binding of the antibody to human apo $B$ since the concentration of human apo $B$ in the plasma of that mouse was identical to that in the human plasma $(\sim 60 \mathrm{mg} / \mathrm{dl})$. 

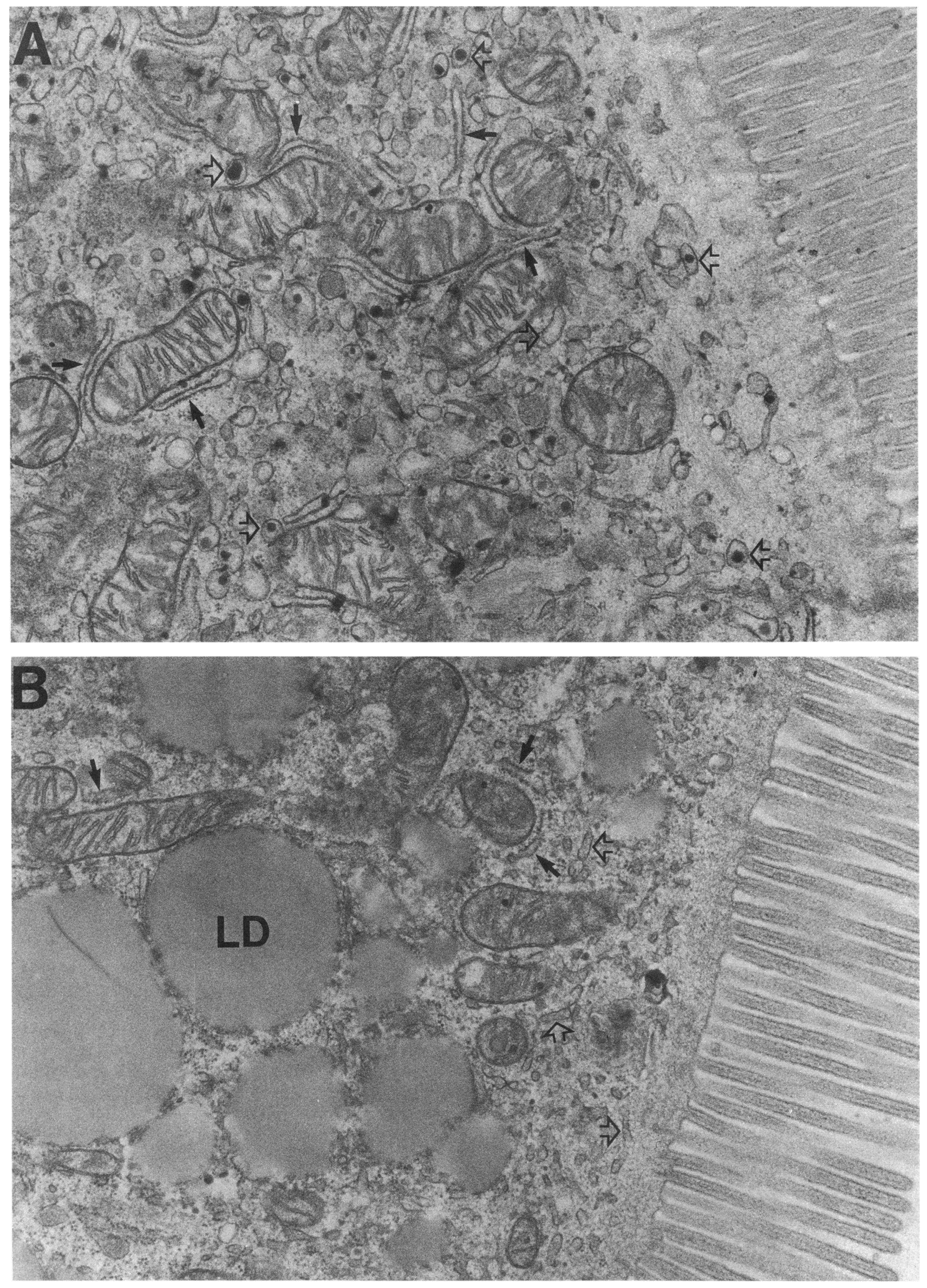

2938 Young et al. 
Although the absence of intestinal apo B synthesis did not appear to diminish the plasma levels of the $\beta$-migrating lipoproteins derived from the liver, it did have a significant effect on the HDL levels. The levels of the $\alpha$-migrating lipoproteins were reduced in the $\mathrm{HuBTg}^{+/ 0}, a p o B^{-1-}$ mice (Fig. $7 \mathrm{~A}$ ), consistent with the HDL cholesterol measurements (Table I). As assessed by Western blots of SDS-polyacrylamide gels, the concentration of apo $\mathrm{AI}$ in the plasma of the $\mathrm{HuBTg}^{+/ 0}, a p o B^{-1-}$ mice was $\sim 25 \%$ of the levels in the $\mathrm{HuBTg}^{+10}$ mice (data not shown).

To further analyze the distribution of cholesterol in the plasma of $\mathrm{HuBTg}^{+/ 0}$, apoB ${ }^{-1-}$ and $\mathrm{HuBTg}^{+/ 0}$ mice, we fractionated pooled plasma samples by size using Superose chromatography. The HuBTg ${ }^{+/ 0}, a p o B^{-1-}$ mice had much lower levels of HDL cholesterol than the HuBTg ${ }^{+/ 0}$ mice, but the levels of LDL cholesterol were no different (Fig. $8 \mathrm{~A}$ ). The absence of intestinal apo B expression did not significantly affect the amount or the distribution of triglycerides in the plasma; both $\mathrm{HuBTg}^{+/ 0}, \mathrm{apoB}^{-1-}$ and HuBTg ${ }^{+/ 0}$ mice had triglyceride-rich LDL (Fig. $8 B$ ). To analyze the distribution of human apo B100 within each column fraction, we performed Western blots of SDS-polyacrylamide gels using ${ }^{125}$ I-labeled $\mathrm{C} 1.4$ as a probe, and then quantified the amount of radioactivity within each apo B100 band. The amount and distribution of human apo B100 in the plasma of $\mathrm{HuBTg}^{+/ 0}, a_{p o B}{ }^{-1-}$ and $\mathrm{HuBTg}^{+/ 0}$ mice were very similar (Fig. $8 \mathrm{C}$ ).

To further examine the impact of the absence of intestinal apo B expression on the plasma levels of the human apo B produced by the liver, we tested the ability of plasma from $\mathrm{HuBTg}^{+/ 0}$, apoB $^{-1-}$ and $\mathrm{HuBTg}^{+/ 0}$ mice to compete with ${ }^{125} \mathrm{I}-$ labeled human LDL for binding to a human apo B-specific mAb (1D1) in a solid-phase, competitive RIA $(7,10)$. The competition curves for the $\mathrm{HuBTg}^{+/ 0}$ mice and the $\mathrm{HuBTg}^{+/ 0}$, $a p o B^{-1-}$ mice were parallel and nearly superimposable (Fig. 9 ), indicating that the absence of apo $B$ expression in the intestines of the $\mathrm{HuBTg}^{+/ 0}$, $a p o B^{-1-}$ mice did not significantly reduce the plasma levels of the apo B-containing lipoproteins that were derived from the liver.

Fat malabsorption in mice lacking apo $B$ expression in the intestine. Several observations strongly suggested that the $\mathrm{HuBTg}^{+/ 0}, \mathrm{apoB}^{-1-}$ mice had significant fat malabsorption: the severe intestinal pathology of both suckling and adult animals, the severe growth retardation during the suckling phase, and the twofold increase in chow consumption by the adult animals. To further evaluate the possibility of fat malabsorption, we performed retinol palmitate absorption tests in four $\mathrm{HuBTg}^{+/ 0}$, $a p o B^{-1-}$ mice and four $\mathrm{HuBTg}^{+/ 0}$ mice. In the $\mathrm{HuBTg}^{+/ 0}$, $a p o B^{-1-}$ mice, the absorption of retinol palmitate was virtually undetectable (Fig. $10 A$ ). Fig. 10, $B$ and $C$ show the HPLC chromatograms for the 2-h time points for an $\mathrm{HuBTg}^{+/ 0}$ mouse and an $\mathrm{HuBTg}^{+/ 0}, a_{\mathrm{poB}} \mathrm{B}^{-1-}$ mouse, respectively. In addition to showing the virtual absence of retinol palmitate in the $\mathrm{HuBTg}^{+/ 0}$, $a p o B^{-1-}$ mouse, the chromatogram revealed that the plasma levels of $\alpha$-tocopherol were extremely low (Fig. $10 C$ ). Using a more sensitive electrochemical $\alpha$-tocopherol detection system (23), the $\alpha$-tocopherol levels in two $\mathrm{HuBTg}^{+/ 0}, a p o B^{-1-}$ mice were 0.96 and $0.63 \mathrm{nmol} / \mathrm{ml}$, versus 12.3 and $9.89 \mathrm{nmol} / \mathrm{ml}$ in two $\mathrm{HuBTg}^{+/ 0}$ mice.

We also examined the percentage of intestinal $\left[{ }^{14} \mathrm{C}\right]-$ cholesterol absorption in $\mathrm{HuBTg}^{+/ 0}, a p o B^{-1-}$ mice and $\mathrm{HuBTg}^{+/ 0}, a p o B^{-1+}$ mice. In the $\mathrm{HuBTg}^{+/ 0}, a_{p o B}{ }^{-1+}$ mice, most of the cholesterol was absorbed, whereas cholesterol absorption was undetectable in the $\mathrm{HuBTg}^{+/ 0}, a p o B^{-1-}$ mice ( $\mathrm{Ta}-$ ble II). We hypothesized that the HuBTg ${ }^{+/ 0}, a p o B^{-1-}$ mice might have increased levels of de novo cholesterol biosynthesis to compensate for the markedly reduced efficiency of cholesterol absorption in the intestine. To obtain an indirect assessment of de novo cholesterol biosynthesis, we compared plasma mevalonate levels in $\mathrm{HuBTg}^{+/ 0}$, apoB $^{-1-}$ and $\mathrm{HuBTg}^{+/ 0}$ mice. In two experiments, the plasma mevalonate levels in the $\mathrm{HuBTg}^{+/ 0}, a p o B^{-1-}$ mice were significantly greater than in the $\mathrm{HuBTg}^{+10}$ mice (Table III).

The intestinal fat malabsorption led us to consider whether the $\mathrm{HuBTg}^{+/ 0}, a p o B^{-1-}$ mice were deficient in essential fatty acids, such as linoleate. In the plasma of 3 -mo-old $\mathrm{HuBTg}^{+/ 0}$, $a p o B^{-1-}$ mice, the amount of linoleate (expressed as a percentage of the total fatty acids) was decreased, and the amount of oleate (a nonessential fatty acid) was increased (Fig. 11). However, the percentages of linoleate were not nearly as low as the values observed in symptomatic rats fed a diet deficient in essential fatty acids (29), suggesting that the $\mathrm{HuBTg}^{+/ 0}$, $a \mathrm{poB}^{-1-}$ mice had the ability to absorb limited amounts of essential fatty acids in a chylomicron-independent fashion. Aside from the oleate and linoleate levels, we did not observe significant differences in the amounts of other fatty acids in the plasma. We did not detect any omega-9 fatty acids that are characteristically observed in essential fatty acid deficiency (29). We measured the fatty acid composition of the lung, heart, spleen, liver, and kidney in a 3-mo-old HuBTg ${ }^{+10}, a_{0 o B}{ }^{-1-}$ mouse and a 3-mo-old $\mathrm{HuBTg}^{+/ 0}$ mouse. The 3-mo-old $\mathrm{HuBTg}^{+/ 0}, a p o B^{-1-}$ mouse had the characteristic severe intestinal pathology associated with that genotype. We observed no differences in tissue fatty acid composition in the two mice (data not shown).

To test the possibility that the massive accumulation of fat in the intestinal enterocytes of the $\mathrm{HuBTg}^{+/ 0}, a p o B^{-1-}$ mice would lead to defective absorption of other nutrients, we performed a D-xylose absorption test. The absorptions of D-xylose in $\mathrm{HuBTg}^{+/ 0}, a p o B^{-1-}$ and $\mathrm{HuBTg}^{+/ 0}$ mice were identical (Fig. 12 ), indicating that the $\mathrm{HuBTg}^{+/ 0}, a p o B^{-1-}$ mice probably do not have a significant defect in the absorption of other nutrients.

\section{Discussion}

In this study, we developed genetically modified mice that synthesized human apo $B$ in the liver but did not synthesize any apo $B$ (mouse or human) in the intestine. These mice were

Figure 4. (A) The apical cytoplasm of duodenal enterocytes of a 2 -wk-old suckling $\mathrm{HuBTg}^{+/ 0}$ mouse revealed large amounts of smooth (open arrows) and rough (black arrows) endoplasmic reticulum membranes containing intensely stained triglyceride-rich particles of VLDL and chylomicron size $(500-1,500 \AA)$. (B) The apical cytoplasm of the duodenal enterocytes of a 2 -wk-old suckling $\mathrm{HuBTg}^{+/ 0}$, apoB ${ }^{-1-}$ mouse are filled with triglyceride-rich lipid droplets $(L D)$. Note the relative deficiency of ER membranes, particularly those lacking ribosomes, and the absence of lipidstaining particles of VLDL and chylomicron size. Both $A$ and $B$ are images of enterocytes located some distance from the villus tip because the enterocytes at the villus tip of $\mathrm{HuBTg}^{+/ 0}$, apoB $^{-1-}$ mice were too fatty to visualize organelles $(\times 24,000)$. 

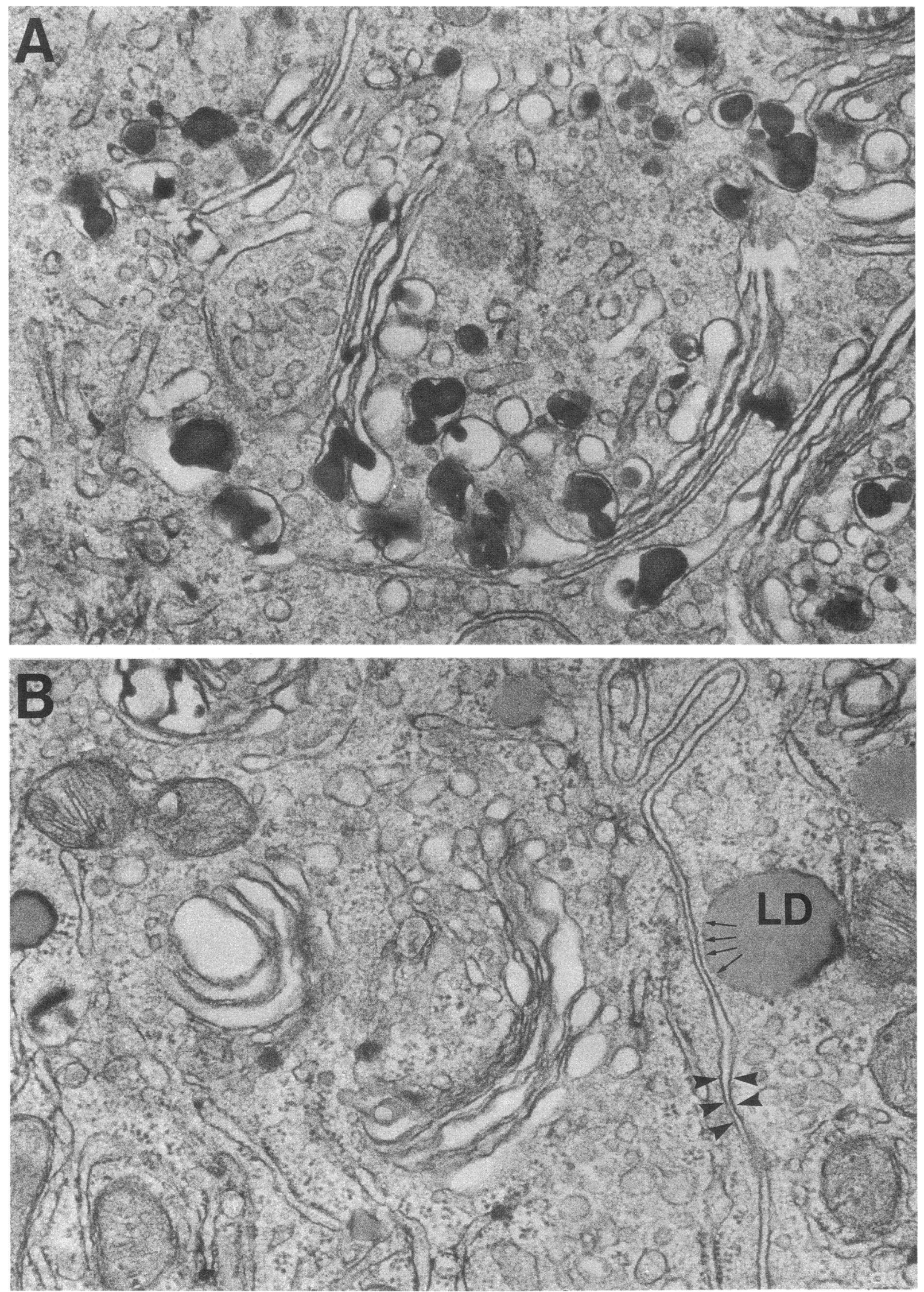

Figure 5. (A) Supranuclear Golgi area of a duodenal enterocyte of a 2-mo-old $\mathrm{HuBTg}^{+/ 0}$ mouse revealed numerous chylomicron-sized ( $\sim 800-$

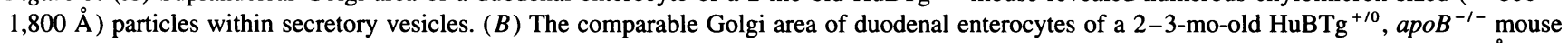
lacked lipid-staining particles. Note that the thickness of the lipid bilayer of a typical cell membrane (black arrowheads) measures $\sim 120 \AA$, whereas the surface layer of the cytosolic lipid droplet is less than half as thick (black arrows) $(\times 42,000)$. 

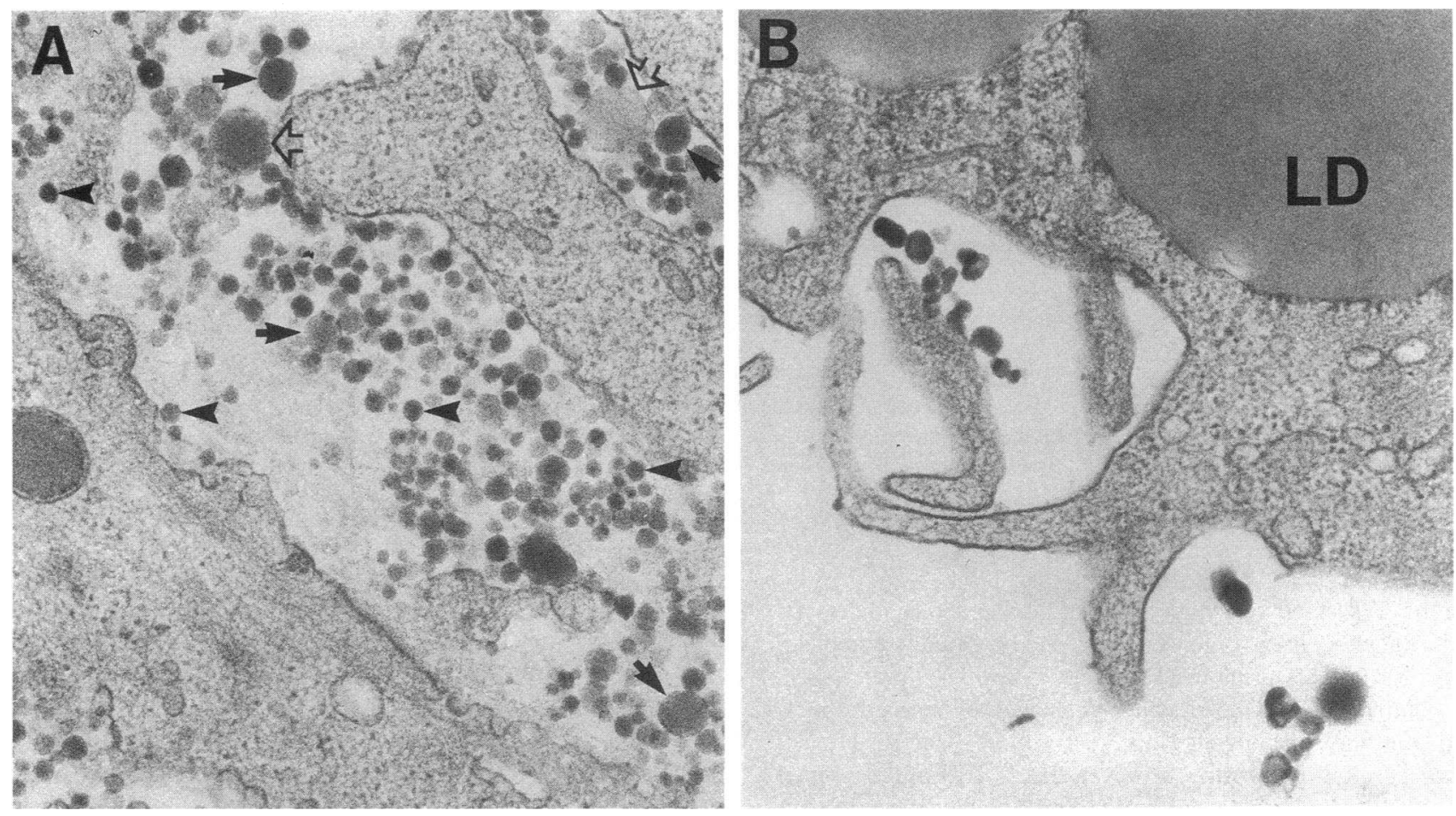

Figure 6. (A) Numerous VLDL- and chylomicron-sized lipid-staining particles $(\sim 700-2,200 \AA)$ are observed in the connective tissues of a villus in the duodenum of a 2 -wk-old suckling HuBTg ${ }^{+/ 0}$ mouse (black arrowheads, $\sim 700 \AA$; black arrows, $\sim 1,200-1,500 \AA$; and open arrows $\sim 2,000-2,200 \AA$ diameters). The particle sizes in this compartment are usually more heterogeneous than the particles within individual enterocytes, presumably because the enterocytes at different locations within the villus synthesize particles of different sizes. $(B)$ In a 2-wk-old suckling $\mathrm{HuBTg}^{+/ 0}$, apoB ${ }^{-1-}$ mouse, very few lipid-staining particles were occasionally observed at the base of the enterocyte, and these tended to be irregular in shape. These particles (which may represent triglyceride droplets lacking apo B) were also rarely observed in the connective tissue core of the villus of the 2-3-mo-old $\mathrm{HuBTg}^{+/ 0}, a p o B^{-1-}$ mice. A large lipid droplet $(L D)$ is seen within the basal cytoplasm of the enterocyte $(\times 36,000)$.

homozygous for a knockout mutation in the mouse apo B gene and possessed a human apo $B$ transgene that was expressed in the liver $(7,8)$ and yolk sac (11), but not in the intestine (10). Suckling mice lacking intestinal apo $B$ expression could be identified easily within $24 \mathrm{~h}$ after birth by a white, protuberant abdomen with dilated loops of small and large intestines, that contained massive amounts of fat within the villus enterocytes. During the suckling phase, while consuming a high fat diet, nearly all of the mice lacking intestinal apo B expression became emaciated and had severe growth retardation. However, about one-third of the animals survived until weaning, and once weaned onto a chow diet, the animals regained their vitality

Table I. Lipid Levels in $\mathrm{HuBTg}^{+/}$and $\mathrm{HuBTg}^{+\infty}$, apoB ${ }^{-/-}$Mice

\begin{tabular}{lccccc}
\hline \multicolumn{1}{c}{ Genotype } & Sex & $n$ & Triglycerides & $\begin{array}{c}\text { Total } \\
\text { cholesterol }\end{array}$ & $\begin{array}{c}\text { HDL } \\
\text { cholesterol }\end{array}$ \\
\hline HuBTg $^{+10}$, apoB $^{-1-}$ & M & 9 & $114 \pm 49$ & $59 \pm 19$ & $16 \pm 7$ \\
HuBTg $^{+10}$ & M & 4 & $107 \pm 50$ & $88 \pm 47$ & $49 \pm 17$ \\
& & & $(P=0.57)$ & $(P=0.06)$ & $(P<0.0001)$ \\
HuBTg $^{+/ 0}$, apoB $^{-/-}$ & F & 9 & $120 \pm 52$ & $98 \pm 50$ & $19 \pm 7$ \\
HuBTg $^{+10}$ & F & 4 & $115 \pm 53$ & $140 \pm 29$ & $51 \pm 21$ \\
& & & $(\mathrm{P}=0.87)$ & $(\mathrm{P}=0.13)$ & $(\mathrm{P}=0.006)$
\end{tabular}

All measurements are means $(\mathrm{mg} / \mathrm{dl}) \pm \mathrm{SD} ; \mathrm{M}$, male; F, female. Statistical differences were determined with an unpaired, two-tailed $t$ test. and attained normal size. Adult mice lacking intestinal apo B expression had essentially no absorption of retinol palmitate or cholesterol, but the absorption of D-xylose was no different than in control mice. Although not measured directly, the absorption of the fat-soluble antioxidant, $\alpha$-tocopherol, must have been severely diminished, as the plasma levels of $\alpha$-tocopherol were extremely low. Thus, the absence of apo B expression in the intestine prevented the formation of chylomicrons and resulted in severe intestinal fat malabsorption. The mice lacking intestinal apo B represent the first murine model of intestinal fat malabsorption.

In prior studies (11), we showed that $a p o B^{-1-}$ embryos could not synthesize apo B in the yolk sac, and we suggested that the lethal developmental abnormality in $a p o B^{-1-}$ embryos was related to absent yolk sac expression of apo B, which could lead to impaired nutrition of the developing embryo. Subsequent ultrastructural studies have revealed the absence of lipoprotein formation in the visceral endoderm cells of the yolk sac of 9.5d-old $a p o B^{-1-}$ embryos (Farese, R. V., Jr., S. Cases, S. L. Ruland, D. A. Sanan, H. J. Kayden, J. S. Wong, S. G. Young, and R. L. Hamilton, manuscript submitted for publication ). The absence of lipoprotein formation in these cells was accompanied by an accumulation of cytosolic lipid droplets (not unlike the accumulation of cytosolic lipid droplets in the intestinal enterocytes of $\mathrm{HuBTg}^{+10}$, apoB ${ }^{-1-}$ mice). We demonstrated that the human apo $B$ transgene, which was expressed in the yolk sac, complemented the developmental abnormality associated with homozygosity for the knockout mutation. Using a transgenic 

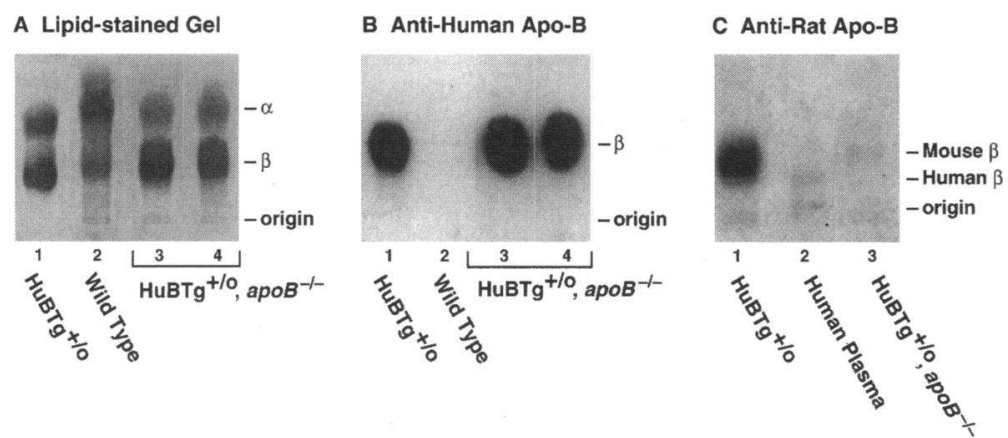

Figure 7. Agarose gel analysis of mouse plasma. (A) A gel stained for neutral lipids with Fat Red 7B. Lane 1, plasma from a $\mathrm{HuBTg}^{+/ 0}$ mouse; lane 2, plasma from a wild-type mouse; lanes 3-4, plasma from two $\mathrm{HuBTg}^{+/ 0}, a p o B^{-1-}$ mice. $(B)$ A Western blot using ${ }^{125} \mathrm{I}-\mathrm{C} 1.4$. Lanes $1-4$ are the same as in $A$. Radioactivity in the pre $\beta$ and $\beta$ bands was quantitated on a phosphorimager (Fuji Medical Systems, USA, Inc.) using a ${ }^{125}$ I-standard. Lane $l$ had 126,163 cpm; lane 3, 116,647 cpm; lane 4, 132,945 cpm. (C) A Western blot using a ${ }^{125}$ I-labeled antibody specific for rat apo B. Lane 1 shows a $\mathrm{HuBTg}^{+10}$ mouse; lane 2, human plasma; lane 3, plasma from a $\mathrm{HuBTg}^{+/ 0}, a p o B^{-1-}$ mouse. To reduce the binding of the antibody to human apo $B$, the antibody was passed over a human LDL-Sepharose 4B column, and the antibody was preincubated with $20 \mu 1$ of human plasma before incubating it with the nitrocellulose membrane. Despite these precautions, there was faint binding of the antibody to the $\beta$-migrating lipoproteins in human plasma and the plasma of the $\mathrm{HuBTg}^{+/ 0}, a p o B^{-1-}$ mouse. The amounts of radioactivity in the pre- $\beta$ and $\beta$ bands were: lane $1,11,443 \mathrm{cpm}$; lane $2,1,189 \mathrm{cpm}$; and lane $3,1,132 \mathrm{cpm}$.

line that expressed very high levels of human apo B, the rescue of the knockout homozygotes appeared to be virtually complete. In the first 236 offspring from $\mathrm{HuBTg}^{+/ 0}, a \mathrm{poB}^{+/-}$intercrosses, we obtained nearly mendelian percentages of rescued apo $B$ knockout mice (genotypes HuBTg ${ }^{+/+}$, $a p o B^{-1-}$ or $\mathrm{HuBTg}^{+/ 0}$, $\left.a p o B^{-1-}\right)$. It is noteworthy, however, that $\sim 10 \%$ of the rescued mice had hydrocephalus. Although the explanation for the hydrocephalus in the rescued mice is not completely clear, hydrocephalus is known to be associated with apo B deficiency during development $(11,28,30)$. Perhaps the human apo $\mathrm{B}$ transgene yielded sufficient yolk sac apo B expression to ensure the survival of the $a \mathrm{poB}^{-1-}$ embryos, but may not have completely restored the levels of yolk sac apo B synthesis to normal, thereby leading to the development of hydrocephalus in some of the rescued mice. If this reasoning is correct, one would predict that a transgenic line expressing low levels of human apo B might be significantly less efficient in rescuing the homozygous knockout mice.

The mice lacking intestinal apo B expression provide the first animal model for the intestinal pathology observed in the human apo B deficiency syndrome, abetalipoproteinemia (26, 27). The development of this model is important, especially in light of inconsistencies and uncertainties regarding cholesterol metabolism and cholesterol absorption in these disorders (31, 32 ). In subjects with abetalipoproteinemia, sterol balance studies have indicated an increased rate of de novo cholesterol biosynthesis (31); however, turnover studies using intravenous $\left[{ }^{14} \mathrm{C}\right]$ cholesterol have not uncovered evidence for increased cholesterol biosynthesis (33). Illingworth et al. (32) have documented increased mevalonate levels in the urine of patients with abetalipoproteinemia, indicating increased cholesterol biosynthesis. In a subsequent study (20), they did not find significantly increased levels of mevalonate in the plasma. Illingworth et al. (31) also measured the cholesterol absorption in three patients with abetalipoproteinemia by the oral administration of $\left[{ }^{3} \mathrm{H}\right]-$ cholesterol and $\left[{ }^{14} \mathrm{C}\right]$ sitosterol, but the results of these studies were open to different interpretations. From the fecal recovery of the radioisotopes, they calculated the absorption of cholesterol to be $\sim 30 \%$ in the subjects with abetalipoproteinemia and $\sim 45 \%$ in the control subjects. However, the amount of $\left[{ }^{3} \mathrm{H}\right]$ cholesterol observed in the plasma of the abetalipoproteinemia patients was $<3 \%$ of that observed in the normals, suggesting that the actual absorption of the $\left[{ }^{3} \mathrm{H}\right]$ cholesterol may have been much lower than suggested by the fecal recovery calculations. In interpreting all of the studies on cholesterol metabolism in abetalipoproteinemia, Illingworth's group (31, 32 ) have concluded that cholesterol absorption is abnormal in patients with abetalipoproteinemia, and that the impaired cholesterol absorption is accompanied by increased synthesis of cholesterol by the liver. Our studies, which showed undetectable levels of cholesterol absorption and markedly increased plasma mevalonate levels in mice lacking intestinal apo B synthesis,
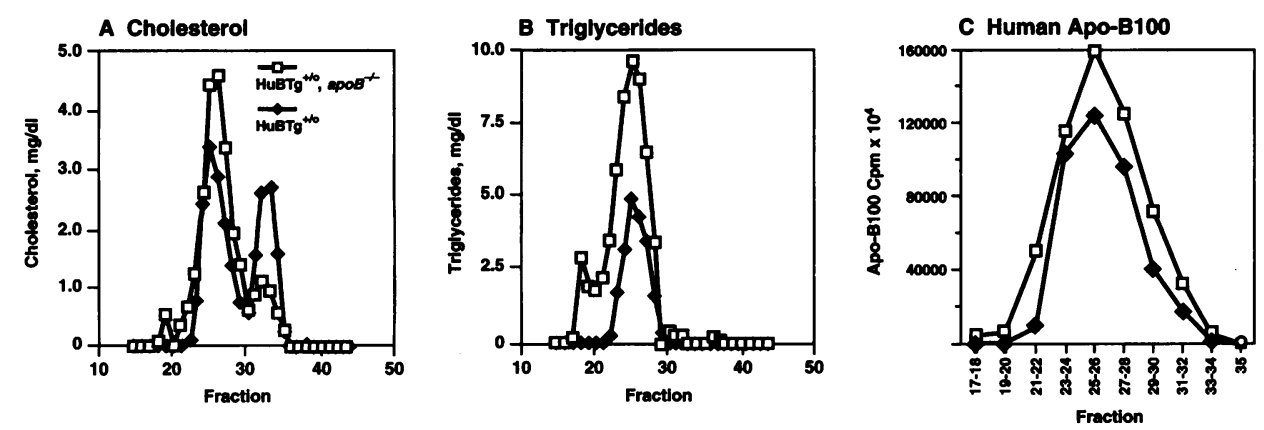

Figure 8. Distribution of cholesterol, triglycerides, and human apo B100 in the plasma of $\mathrm{HuBTg}^{+/ 0}$, apoB ${ }^{-1-}$ and $\mathrm{HuBTg}^{+/ 0}$ mice. Plasma was obtained from three female animals of each genotype, pooled, and fractionated on a Superose $610 / 30$ column. Cholesterol and triglyceride concentrations in each column fraction were determined by an enzymatic assay. The relative amounts of human apo B100 in each fraction were determined by scanning Western blots of an SDS-polyacrylamide gel, using ${ }^{125} \mathrm{I}-\mathrm{C} 1.4$. The amount of radioactivity in each band was determined using the Fuji phosphorimager. 


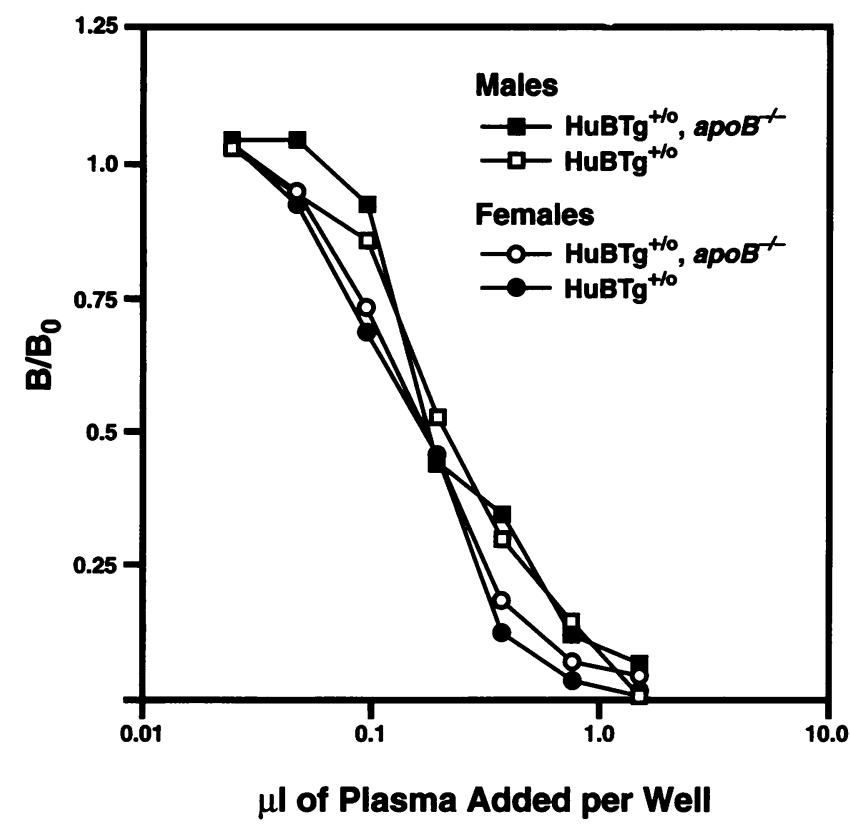

Figure 9. Competitive RIA assessing the ability of the plasma from male and female $\mathrm{HuBTg}^{+/ 0}$, apoB ${ }^{-1-}$ and $\mathrm{HuBTg}^{+/ 0}$ mice to compete with ${ }^{125} \mathrm{I}$-LDL for binding to the human apo B-specific mAb, 1D1. The RIA using antibody 1D1 measured both human apo B48 and human apo $B 100(16) . B$ and $B_{0}$ represent the specific ${ }^{125} I$ counts bound in the presence and the absence of competitor, respectively. The human apo $\mathrm{B}$ concentrations in the male and female $\mathrm{HuBTg}^{+/ 0}, a p o B^{-1-}$ mice in this experiment were 57.3 and $79.3 \mathrm{mg} / \mathrm{dl}$, respectively; the human apo B concentrations in the male and female $\mathrm{HuBTg}^{+/ 0}$ mice were 50.7 and $79.2 \mathrm{mg} / \mathrm{dl}$, respectively. Identical results were obtained with the plasma from several other pairs of $\mathrm{HuBTg}^{+/ 0}, a p o B^{-1-}$ and $\mathrm{HuBTg}^{+/ 0}$ mice. We also found identical results with a competitive RIA using the human apo B100-specific mAb, MB47. Antibody MB47 detects apo B100 but not apo B48. We expected to find similar results in the RIAs using antibodies 1D1 and MB47 because the ratio of apo B100 to apo B48 in the plasma of the $\mathrm{HuBTg}^{+/ 0}, a_{p o B}{ }^{-1-}$ and $\mathrm{HuBTg}^{+/ 0}$ mice were identical, as judged by Western blots of SDS-polyacrylamide gels (data not shown).

provide strong support for the view that absent chylomicron secretion does indeed cause severe cholesterol malabsorption associated with increased de novo synthesis of cholesterol.
Table II. Cholesterol Absorption in $\mathrm{HuBTg}^{+\infty}$, apoB ${ }^{-/-}$Mice

\begin{tabular}{cc}
\hline & {$\left[{ }^{14} \mathrm{C}\right]$ cholesterol absorption } \\
\hline & $\%$ \\
$\mathrm{HuBTg}^{+/ 0}$, apoB $^{-/-}$mice & \\
Mouse 1 & 0 \\
Mouse 2 & 0 \\
$\mathrm{HBTg}^{+/ 0}$, apo $^{+/-}$mice & \\
Mouse 1 & 89.0 \\
Mouse 2 & 63.7 \\
Mouse 3 & 74.6 \\
\hline
\end{tabular}

The animals in the two groups were similar in weight. The $\mathrm{HuBTg}^{+/ 0}$, $a p o B^{-1-}$ mice had a mean age of $6 \mathrm{wk}$; the mean age of the $\mathrm{HuBTg}^{+/ 0}, \operatorname{apoB}^{+/-}$mice was 15 wk. Statistical differences were determined with an unpaired, two-tailed $t$ test.

The ultrastructural studies reported here have clarified the pathological features of intestinal apo B deficiency, particularly the fat compartmentalization in the fatty enterocytes. Our findings, which are based on 500 electron micrographs of thin sections of fatty enterocytes, established that the vast majority of the intracellular lipid droplets were cytosolic (i.e., not within membrane-bound compartments of the endoplasmic reticulum or Golgi apparatus). This conclusion differs from an early report on the ultrastructural features of fatty enterocytes of human subjects with abetalipoproteinemia, in which many of the intracellular lipid droplets were thought to be membrane bound (34). In that study, the photomicrographs demonstrated that most of the lipid droplets were cytosolic, although the author concluded that many were membrane bound because the surface coating of the droplets was electron dense. However, the thickness of the electron-dense surface film of the lipid droplets was not measured and compared with that of the cell membrane. In our studies, we showed that the surface film of the cytosolic lipid droplets was less than half the thickness of the plasma membrane (Fig. 5), consistent with a monomolecular surface layer of phospholipid. A second morphologic feature that distinguishes membrane-bound lipid droplets is the presence of an electron-lucent space between the membrane bilayer and the lipid droplet. No electron-lucent space surrounding the lipid
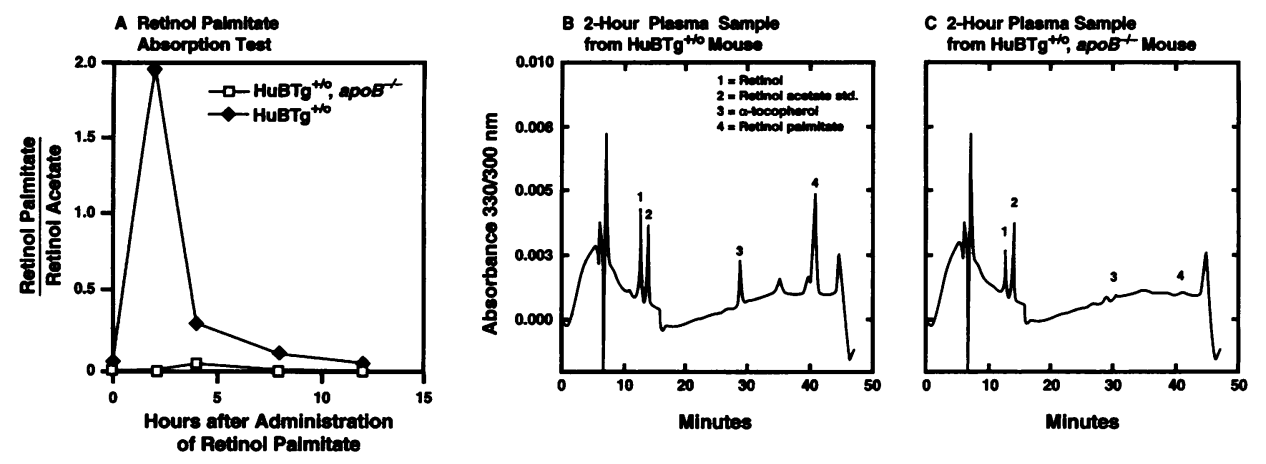

Figure 10. (A) Absorption of retinol palmitate in an $\mathrm{HuBTg}^{+/ 0}, a_{p o B^{-/-}}$ mouse and an $\mathrm{HuBTg}^{+/ 0}$ mouse. $B$ and $C$ show the HPLC chromatograms for the 2-h time point for studies on the $\mathrm{HuBTg}^{+/ 0}$ mouse and the $\mathrm{HuBTg}^{+/ 0}$, apoB $^{-1-}$ mouse, respectively. In four other pairs of animals, we observed similar results: a retinol palmitate absorption peak at $2 \mathrm{~h}$ in the $\mathrm{HuBTg}^{+/ 0}$ mice, and either trace or absent absorption of retinal palmitate in the $\mathrm{HuBTg}^{+/ 0}, a_{a p B^{-1-}}$ mice. In the $\mathrm{HuBTg}^{+/ 0}, a p o B^{-1-}$ mice with the trace amounts of retinol palmitate absorption, the peak absorption appeared to be at $4-8 \mathrm{~h}$, rather than at $2 \mathrm{~h}$. All animals were 5 mo old. 


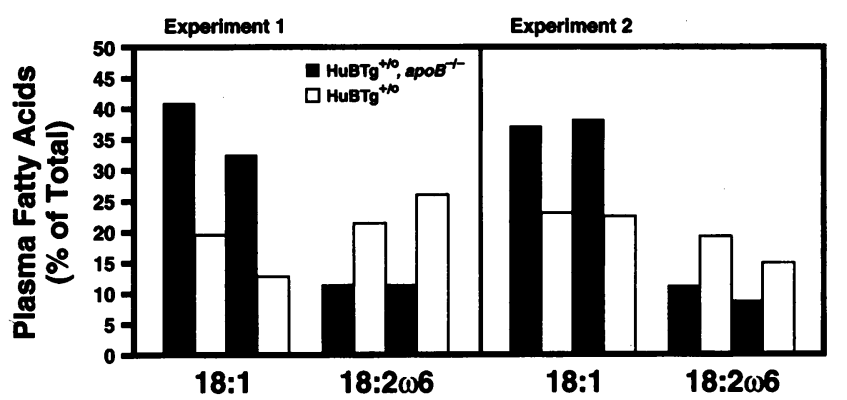

Figure 11. Analysis of the oleate and linoleate content of the plasma lipids of $\mathrm{HuBTg}^{+/ 0}$, apoB $^{-1-}$ and $\mathrm{HuBTg}^{+/ 0}$ mice. In each experiment, analyses were performed on two 3-mo-old $\mathrm{HuBTg}^{+/ 0}$, apoB ${ }^{-1-}$ mice and two $\mathrm{HuBTg}^{+/ 0}$ mice. The HuBTg ${ }^{+/ 0}, a p o B^{-1-}$ mice had reduced amounts of linoleate and increased amounts of oleate (expressed as a percentage of total plasma fatty acids), compared with the HuBTg ${ }^{+/ 0}$ mice.

droplets was observed in the enterocytes of mice lacking intestinal apo $B$ synthesis (see Figs. $4 B, 5 B$, and $6 B$ ). In another study on abetalipoproteinemia, Bouma et al. suggested that the lipid droplets were cytoplasmic, not membrane bound, even though the magnification of their photomicrographs was too low to resolve the two distinguishing morphological features described above (35). The results of our studies in the mouse model strongly suggest that the vast majority of the lipid droplets in the fatty enterocytes of abetalipoproteinemia are located in cytosolic lipid droplets, not in the membrane-bound organelles of the secretory pathway.

The mice that lack intestinal apo B synthesis provide an animal phenocopy for the human condition, chylomicron retention disease (36). Human subjects with this disorder have a defect in chylomicron secretion with membrane-bound fat droplets in both ER and Golgi apparatus associated with fat-filled enterocytes and intestinal fat malabsorption, but they do not appear to have a defect in hepatic lipoprotein synthesis (36). The molecular basis for this syndrome is unknown, although genetic studies have excluded linkage to the apo B gene (37). In comparing the lipoprotein phenotypes of human patients with chylomicron retention disease and the mice lacking intestinal apo B synthesis, several findings are noteworthy. First, patients with chylomicron retention disease have levels of LDL-apo B that are significantly lower than controls (36). In contrast, the absence of chylomicron formation in mice did not appear to have an effect on the plasma levels of liver-derived lipoproteins

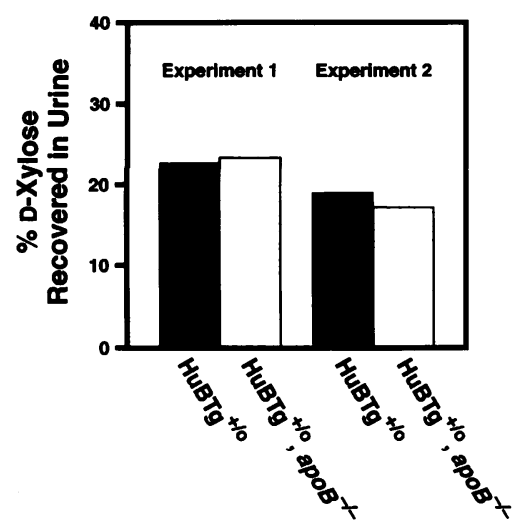

Figure 12. Absorption of D-xylose in four $\mathrm{HuBTg}^{+/ 0}$, apoB $^{-1-}$ mice and four $\mathrm{HuBTg}^{+/ 0}$ mice. Animals were given free access to water containing $\mathrm{D}$-xylose for $24 \mathrm{~h}$, and the percentage of D-xylose recovered in the urine was determined.
Table III. Plasma Mevalonate Levels (pmol/ml) in Mice Lacking $A p o B$ in the Intestine

\begin{tabular}{llll}
\hline \multicolumn{2}{r}{$\mathrm{HuBTg}^{+\infty}$, apoB $^{-1-}$} & \multicolumn{2}{c}{$\mathrm{HuBTg}^{+\infty}$} \\
\hline Experiment 1 & & & \\
Mouse 1 & 226.5 & mouse 1 & 168.3 \\
Mouse 2 & 276.9 & mouse 2 & 161.5 \\
Mouse 3 & 258.9 & mouse 3 & 195.1 \\
Mouse 4 & 232.5 & mouse 4 & 178.8 \\
Mean \pm SD & $248.6 \pm 23.5$ & & $175.7 \pm 14.6$ \\
& & & $(P=0.002)$ \\
Experiment 2 & & & \\
Mouse 5 & 305.8 & mouse 5 & 103.4 \\
Mouse 6 & 334.8 & mouse 6 & 137.7 \\
Mouse 7 & 258.9 & mouse 7 & 90.8 \\
Mean \pm SD & $304.2 \pm 31.4$ & & $110.7 \pm 24.3$ \\
& & & $(P=0.001)$ \\
\hline
\end{tabular}

(see Figs. $7 A, 7 B, 8 A, 8 C$, and 9). Second, human patients with chylomicron retention disease have markedly reduced HDL cholesterol levels, a finding that is identical to our results in the mice lacking intestinal apo B synthesis. Although the metabolic explanation for reduced HDL levels has not been thoroughly investigated, either in the mice or the affected humans, the marked HDL lowering in both strongly suggests that chylomicron secretion is fundamentally important for the maintenance of normal plasma levels of HDL.

In humans with abetalipoproteinemia and chylomicron retention disease, $\alpha$-tocopherol deficiency is a significant clinical problem and can, over a period of years, lead to severe neurologic disease unless the patients are treated with high doses of $\alpha$-tocopherol (26). Our mice lacking intestinal apo B had extremely low levels of $\alpha$-tocopherol, similar to the levels observed in patients with abetalipoproteinemia (38). Although we have not yet observed clinical signs of neurologic disease (e.g., ataxia) in the $\alpha$-tocopherol-deficient mice, we have not yet performed neuropathological studies to look for subtle neurological changes. Vitamin E deficiency in rats is known to cause sterility (39). We have not yet systematically examined the fertility of our $\alpha$-tocopherol-deficient mice. Our preliminary studies have suggested that the chow-fed animals do not have normal fertility. However, we recently set up breeding pairs of male and female $\mathrm{HuBTg}^{+/ 0}, a_{p o B}{ }^{-1-}$ mice on a special diet with a 91-fold enrichment in $\alpha$-tocopherol. On this diet, the tocopherol levels did not change. However, one female became pregnant and had seven pups. Each of the seven pups had the characteristic phenotype of the $\mathrm{HuBTg}^{+/ 0}, a p o B^{-/-}$mice.

Although the mice lacking intestinal apo $B$ production had markedly abnormal absorption of cholesterol and retinol palmitate, the animals did not have severely reduced levels of essential fatty acids in their plasma or tissues. In our experiments, the chow-fed mice had $\sim 50 \%$ reductions in linoleate levels in the plasma, but this modest reduction would not be expected to produce pathologic consequences (29). The absence of severe essential fatty acid deficiency in the mice is consistent with the absence of severe essential fatty acid deficiency in human patients with abetalipoproteinemia. Dr. H. Kayden (40) has found that patients with abetalipoproteinemia have mild-moderate reductions in essential fatty acids but do not manifest symptoms 
of essential fatty acid deficiency. This finding strongly suggests that mammals have the capacity to absorb adequate amounts of essential fatty acids independent of chylomicron formation. In rats fed isotopic long-chain fatty acids, it has been estimated that substantial amounts of unsaturated fatty acids may be absorbed directly into portal vein blood (41-43). A possible mechanism for chylomicron-independent absorption of essential fatty acids is that the essential fatty acids could be secreted into the plasma in association with other apolipoproteins, such as apo AIV or apo AI. The latter possibility could be addressed in genetic studies using mice with knockout mutations in the apo AI-CIIIAIV locus (e.g., one could test whether the $\mathrm{HuBTg}^{+/ 0}, a p o B^{-1-}$ mice might develop severe essential fatty acid deficiency if they were also homozygous for a knockout mutation in the apo AI and/or apo AIV genes). Another possible mechanism is that a few triglyceride droplets lacking apo B might find their way through the secretory pathway of intestinal cells. In rat hepatocytes, Hamilton et al. $(44,45)$ suggested that VLDL assembly is a two-step process involving the fusion of apo B-free triglyceride droplets made in the smooth endoplasmic reticulum with lipid-poor apo B-containing particles made in the rough endoplasmic reticulum. In the absence of apo B synthesis, we speculate that a very small number of triglyceride droplets might find their way through the secretory pathway and out of the cell. Even extremely inefficient movement of lipids through the secretory pathway might explain why humans with abetalipoproteinemia and mice lacking intestinal apo B synthesis are apparently able to absorb some essential fatty acids. The same process could also explain the trace absorption of retinol palmitate and $\alpha$-tocopherol in the absence of apo B.

One of the most intriguing aspects of this study was that the absence of apo B expression in the intestine had no effect on the plasma levels of the apo B-containing lipoproteins derived from the liver. The plasma levels of LDL cholesterol and human apo B in the adult mice lacking intestinal apo B synthesis $\left(\mathrm{HuBTg}^{+/ 0}, a_{p o B^{-1-}}\right)$ were not significantly different than the levels in mice that had normal levels of intestinal apo B synthesis $\left(\mathrm{HuBTg}^{+/ 0}\right)$, at least in the adult animals on a low-fat chow diet. This result was somewhat surprising because it might reasonably be expected that reduced absorption of dietary lipids and the absence of chylomicron remnant delivery to the liver would reduce the plasma levels of the hepatic apo B-containing lipoproteins (46). After all, reducing dietary fat consumption in humans and experimental animals lowers the plasma levels of LDL cholesterol (47). Moreover, many studies of apo B secretion in cultured cells have suggested that lipid availability governs the efficiency of apo B secretion. For example, it is possible to reduce apo $\mathrm{B}$ secretion from cultured hepatoma cells by reducing the concentration of oleate in the cell culture medium (48-51). The observation that the mice lacking intestinal apo $B$ expression have preserved plasma levels of the hepatic apo B-containing lipoproteins obviously requires further evaluation.

\section{Acknowledgments}

We thank J. McGuire for performing plasma fatty acid composition analysis, Poupak Mazda for electron microscopy, R. Milne and Y. Marcel (Ottawa Heart Institute, Ottawa, Canada) for mAb 1D1, N. Davidson for the antisera to rat apo AI, R. Illingworth and H. Kayden for helpful discussions, J. Fisler and J. Lusis for measuring mouse carcass composition, and M. Traber for measurements of $\alpha$-tocopherol levels.
This work was supported by National Institutes of Health grant PO1HL-47660.

\section{References}

1. Young, S. G. 1990. Recent progress in understanding apolipoprotein B Circulation. 82:1574-1594.

2. Gregg, R. E., and J. R. Wetterau. 1994. The molecular basis of abetalipoproteinemia. Curr. Opin. Lipidol. 5:81-86.

3. Linton, M. F., R. V. Farese, Jr., and S. G. Young. 1993. Familial hypobetalipoproteinemia. J. Lipid Res. 34:521-541.

4. Demmer, L. A., M. S. Levin, J. Elovson, M. A. Reuben, A. J. Lusis, and J. I. Gordon. 1986. Tissue-specific expression and developmental regulation of the rat apolipoprotein B gene. Proc. Natl. Acad. Sci. USA. 83:8102-8106.

5. Hopkins, B., C. R. Sharpe, F. E. Baralle, and C. F. Graham. 1986. Organ distribution of apolipoprotein gene transcripts in 6-12 week postfertilization human embryos. J. Embryol. Exp. Morphol. 97:177-187.

6. Shi, W. -K., and J. K. Heath. 1984. Apolipoprotein expression by murine visceral yolk sac endoderm. J. Embryol. Exp. Morphol. 81:143-152.

7. Linton, M. F., R. V. Farese, Jr., G. Chiesa, D. S. Grass, P. Chin, R. E. Hammer, H. H. Hobbs, and S. G. Young. 1993. Transgenic mice expressing high plasma concentrations of human apolipoprotein B100 and lipoprotein(a). J. Clin. Invest. 92:3029-3037.

8. Young, S. G., R. V. Farese, Jr., V. R. Pierotti, S. Taylor, D. S. Grass, and M. F. Linton. 1994. Transgenic mice expressing human $\mathrm{apoB}_{100}$ and $a \mathrm{apoB}_{48}$. Curr. Opin. Lipidol. 5:94-101.

9. McCormick, S. P. A., M. F. Linton, and S. G. Young. 1994. Expression of P1 DNA in mammalian cells and transgenic mice. Genet. Anal. Tech. Appl. 11:158-164.

10. Purcell-Huynh, D. A., R. V. Farese, Jr., D. F. Johnson, L. M. Flynn, V. Pierotti, D. L. Newland, M. F. Linton, D. A. Sanan, and S. G. Young. 1995. Transgenic mice expressing high levels of human apolipoprotein B develop severe atherosclerotic lesions in response to a high-fat diet. J. Clin. Invest. 95:22462257.

11. Farese, R. V., Jr., S. L. Ruland, L. M. Flynn, R. P. Stokowski, and S. G. Young. 1995. Knockout of the mouse apolipoprotein B gene results in embryonic lethality in homozygotes and protection against diet-induced hypercholesterolemia in heterozygotes. Proc. Natl. Acad. Sci. USA. 92:1774-1778.

12. Angermüller, S., and H. D. Fahimi. 1982. Imidazole-buffered osmium tetroxide: an excellent stain for visualization of lipids in transmission electron microscopy. Histochem. J. 14:823-835.

13. Fisler, J. S., C. H. Warden, M. J. Pace, and A. J. Lusis. 1993. BSB: a new mouse model of multigenic obesity. Obes. Res. 1:271-280.

14. Young, S. G., S. J. Bertics, L. K. Curtiss, and J. L. Witztum. 1987. Characterization of an abnormal species of apolipoprotein B, apolipoprotein B37, associated with familial hypobetalipoproteinemia. J. Clin. Invest. 79:18311841.

15. Krul, E. S., Y. Kleinman, M. Kinoshita, B. Pfleger, K. Oida, A. Law, J. Scott, R. Pease, and G. Schonfeld. 1988. Regional specificities of monoclonal anti-human apolipoprotein B antibodies. J. Lipid Res. 29:937-947.

16. Pease, R. J., R. W. Milne, W. K. Jessup, A. Law, P. Provost, J. -C. Fruchart, R. T. Dean, Y. L. Marcel, and J. Scott. 1990. Use of bacterial expression cloning to localize the epitopes for a series of monoclonal antibodies against apolipoprotein B100. J. Biol. Chem. 265:553-568.

17. Young, S. G., S. J. Bertics, T. M. Scott, B. W. Dubois, L. K. Curtiss, and J. L. Witztum. 1986. Parallel expression of the MB19 genetic polymorphism in apoprotein B-100 and apoprotein B-48. Evidence that both apoproteins are products of the same gene. J. Biol. Chem. 261:2995-2998.

18. Peng, Y. -S., and Y. -M. Peng. 1992. Simultaneous liquid chromatographic determination of carotenoids, retinoids, and tocopherols in human buccal mucosal cells. Cancer Epidemiol. Biomarkers Prev. 1:375-382.

19. Turley, S. D., B. P. Daggy, and J. M. Dietschy. 1994. Psyllium augments the cholesterol-lowering action of cholestyramine in hamsters by enhancing sterol loss from the liver. Gastroenterology. 107:444-452.

20. Pappu, A. S., and D. R. Illingworth. 1994. Diurnal variations in the plasma concentrations of mevalonic acid in patients with abetalipoproteinaemia. Eur. $J$. Clin. Invest. 24:698-702.

21. Popják, G., G. Boehm, T. S. Parker, J. Edmond, P. A. Edwards, and A. M. Fogelman. 1979. Determination of mevalonate in blood plasma in man and rat. Mevalonate "tolerance" tests in man. J. Lipid Res. 20:716-728.

22. Mahley, R. W., K. E. Palaoglu, Z. Atak, J. Dawson-Pepin, A. -M. Langlois, V. Cheung, H. Onat, P. Fulks, L. L. Mahley, F. Vakar, et al. 1995. Turkish heart study: lipids, lipoproteins, and apolipoproteins. J. Lipid Res. 36:839-859.

23. Lang, J. K., K. Gohil, and L. Packer. 1986. Simultaneous determination of tocopherols, ubiquinols, and ubiquinones in blood, plasma, tissue homogenates, and subcellular fractions. Anal. Biochem. 157:106-116.

24. Zimmer, J. P., S. M. Lewis, and J. L. Moyer. 1993. Comparison of gavage, water bottle, and a high-moisture diet bolus as dosing methods for quantitative 
D-xylose administration to B6D2F1 (Mus musculus) mice. Lab. Anim. (Lond.). 27:164-170.

25. Eberts, T. J., R. H. B. Sample, M. R. Glick, and G. H. Ellis. 1979. A simplified, colorimetric micromethod for xylose in serum or urine, with phloroglucinol. Clin. Chem. 25:1440-1443.

26. Rader, D. J., and H. B. Brewer, Jr. 1993. Abetalipoproteinemia. New insights into lipoprotein assembly and vitamin $\mathrm{E}$ metabolism from a rare genetic disease. JAMA (J. Am. Med. Assoc.). 270:865-869.

27. Scully, R. E., E. J. Mark, W. F. McNeely, and B. U. McNeely. 1992. Weekly clinicopathological exercises. Case 35-1992. N. Engl. J. Med. 327:628635.

28. Homanics, G. E., T. J. Smith, S. H. Zhang, D. Lee, S. G. Young, and N. Maeda. 1993. Targeted modification of the apolipoprotein B gene results in hypobetalipoproteinemia and developmental abnormalities in mice. Proc. Natl. Acad. Sci. USA. 90:2389-2393. 347.

29. Holman, R. T. 1951. Essential fatty acid deficiency. Nutr. Rev. 9:275-

30. Homanics, G. E., N. Maeda, M. G. Traber, H. J. Kayden, D. B. Dehart, and K. K. Sulik. 1995. Exencephaly and hydrocephaly in mice with targeted modification of the apolipoprotein B (Apob) gene. Teratology. 51:1-10.

31. Illingworth, D. R., W. E. Connor, D. S. Lin, and J. Diliberti. 1980. Lipid metabolism in abetalipoproteinemia: a study of cholesterol absorption and sterol balance in two patients. Gastroenterology. 78:68-75.

32. Illingworth, D. R., A. S. Pappu, and R. E. Gregg. 1989. Increased urinary mevalonic acid excretion in patients with abetalipoproteinemia and homozygous hypobetalipoproteinemia. Atherosclerosis. 76:21-27.

33. Goodman, D. S., R. J. Deckelbaum, R. H. Palmer, R. B. Dell, R. Ramakrishnan, G. Delpre, Y. Beigel, and M. Cooper. 1983. Cholesterol turnover and metabolism in two patients with abetalipoproteinemia. J. Lipid Res. 24:16051611.

34. Dobbins, W. O., III. 1966. An ultrastructural study of the intestinal mucosa in congenital $\beta$-lipoprotein deficiency with particular emphasis upon the intestinal absorptive cell. Gastroenterology. 50:195-210.

35. Bouma, M. E., I. Beucler, M. Pessah, C. Heinzmann, A. J. Lusis, H. Y. Naim, T. Ducastelle, B. Leluyer, J. Schmitz, R. Infante, and L. P. Aggerbeck. 1990. Description of two different patients with abetalipoproteinemia: synthesis of a normal-sized apolipoprotein B-48 in intestinal organ culture. J. Lipid Res. $31: 1-15$.

36. Roy, C. C., E. Levy, P. H. R. Green, A. Sniderman, J. Letarte, J.-P. Buts, J. Orquin, P. Brochu, A. M. Weber, C. L. Morin, et al. 1987. Malabsorption, hypocholesterolemia, and fat-filled enterocytes with increased intestinal apoprotein B. Chylomicron retention disease. Gastroenterology. 92:390-399.
37. Strich, D., R. Goldstein, A. Phillips, R. Shemer, Y. Goldberg, A. Razin, and S. Freier. 1993. Anderson's disease: no linkage to the apo B locus. J. Pediatr. Gastroenterol. Nutr. 16:257-264.

38. Traber, M. G., D. Rader, R. V. Acuff, H. B. Brewer, Jr., and H. J. Kayden. 1994. Discrimination between RRR- and all-racemic- $\alpha$-tocopherols labeled with deuterium by patients with abetalipoproteinemia. Atherosclerosis. 108:27-37.

39. Umer, J. A. 1931. The intra-uterine changes in the pregnant albino rat (Mus norvegicus) deprived of vitamin E. Anat. Rec. 50:175-187.

40. Kayden, H. J. 1980. Is essential fatty acid deficiency part of the syndrome of abetalipoproteinemia? Nutr. Rev. 38:244-246.

41. Mansbach, C. M., II, and R. F. Dowell. 1993. Portal transport of long acyl chain lipids: effect of phosphatidylcholine and low infusion rates. Am. J. Physiol. 264:G1082-G1089.

42. McDonald, G. B., D. R. Saunders, M. Weidman, and L. Fisher. 1980 Portal venous transport of long-chain fatty acids absorbed from rat intestine. Am. J. Physiol. 239:G141-G150.

43. Hyun, S. A., G. V. Vahouny, and C. R. Treadwell. 1967. Portal absorption of fatty acids in lymph- and portal vein-cannulated rats. Biochim. Biophys. Acta. 137:296-305.

44. Alexander, C. A., R. L. Hamilton, and R. J. Havel. 1976. Subcellular localization of B apoprotein of plasma lipoproteins in rat liver. J. Cell Biol. 69:241-263.

45. Hamilton, R. L. 1994. Apolipoprotein-B-containing plasma lipoproteins in health and in disease. Trends Cardiovasc. Med. 4:131-139.

46. Craig, W. Y., R. Nutik, and A. D. Cooper. 1988. Regulation of apoprotein synthesis and secretion in the human hepatoma Hep G2. The effect of exogenous lipoprotein. J. Biol. Chem. 263:13880-13890.

47. Consensus Conference. 1985. Lowering blood cholesterol to prevent heart disease. JAMA (J. Am. Med. Assoc.). 253:2080-2086.

48. Borén, J., M. Wettesten, A. Sjöberg, T. Thorlin, G. Bondjers, O. Wiklund, and S. -O. Olofsson. 1990. The assembly and secretion of apoB 100 containing lipoproteins in Hep G2 cells. Evidence for different sites for protein synthesis and lipoprotein assembly. J. Biol. Chem. 265:10556-10564.

49. Boström, K., J. Borén, M. Wettesten, A. Sjöberg, G. Bondjers, O. Wiklund, P. Carlsson, and S. -O. Olofsson. 1988. Studies on the assembly of apo B-100containing lipoproteins in HepG2 cells. J. Biol. Chem. 263:4434-4442.

50. Dixon, J. L., S. Furukawa, and H. N. Ginsberg. 1991. Oleate stimulates secretion of apolipoprotein B-containing lipoproteins from Hep G2 cells by inhibiting early intracellular degradation of apolipoprotein B. J. Biol. Chem. 266:50805086.

51. Dixon, J. L., and H. N. Ginsberg. 1993. Regulation of hepatic secretion of apolipoprotein B-containing lipoproteins: information obtained from cultured liver cells. J. Lipid Res. 34:167-179. 